WORKING PAPER N² 2017 - 19

Can I Stay or Should I Go? Mandatory Retirement and Labor Force Participation of Older Workers

Simon Rabaté

JEL Codes: J26, J21, J23

Keywords: Retirement, Employment, Labor demand

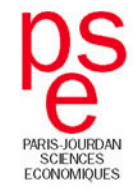




\title{
Can I Stay or Should I Go? Mandatory Retirement and Labor Force Participation of Older Workers *
}

\author{
Simon Rabaté ${ }^{\dagger}$ \\ Thursday $16^{\text {th }}$ February, 2017
}

\begin{abstract}
Retirement is commonly described as a pure labor supply decision, despite the potential importance of the demand side channel. This is partly due to the fact that both dimensions are often difficult to disentangle. In this paper, I manage to overcome this difficulty by using a unique natural experiment, the progressive ban of mandatory retirement in France in the 2000s. Drawing on an extensive administrative dataset, I use inter-industry reforminduced variations in mandatory retirement legislation, thereby insulating this factor from other determinants of retirement, such as financial incentives. I find that demand-side determinants through mandatory retirement do affect retirement patterns: exit rates from employment are estimated to be $6 \%$ higher when mandatory retirement is possible. Secondly, as the mandatory retirement age coincides with the full rate age, I exhibit a previously uncovered determinant of the large bunching in retirement distribution at this age. Mandatory retirement is estimated to explain $10 \%$ of the observed spike at full rate.
\end{abstract}

Keywords: Retirement · Employment · Labor demand

JEL: J26 · J21 · J23

${ }^{*}$ I am grateful to the Caisse nationale d'assurance vieillesse for hosting me and giving my research access to the data. I thank Luc Behaghel, Didier Blanchet, Antoine Bozio, Pascale Breuil, Jonathan Goupille-Lebret, Anne Lavigne, Mélina Ramos-Gorand, Julie Rochut and Marianne Tenand for their valuable comments on this work, and to numerous seminar participants for helpful suggestions. All errors are my own.

${ }^{\dagger}$ Paris School of Economics (PSE)- École normale supérieure (ENS). Contact: simon.rabate@ipp.eu. Address: 48 boulevard Jourdan, 75014 Paris France. 


\section{Introduction}

Increasing the average retirement age is the most common option that policy makers choose to relieve financial pressure over public pension systems. The financial sustainability of the system consequently depends on the evolution of labor force participation at older ages. It is essential, therefore, to understand the mechanisms underlying retirement behaviors.

In France as in most OCDE countries, the evolution of the labor force participation of older workers has followed a U-shape pattern (Schirle, 2008): since the early 2000s, after several decades of steep decline, employment rates have started to increase sharply. The underlying causes of this trend reversal are not fully understood thus far. The two main explanations usually brought forward in France are the shutdown of most early retirement in main public pension schemes and the strengthening of financial incentives to pursued activity (actuarial adjustment beyond the full rate age or decrease in replacement rates). The relative role of each of these potential causes is difficult to identify, as many reforms were implemented within a short period of time.

This article focuses on another overlooked yet potentially important channel: labor demandinduced retirement. This channel is explored through the impact of mandatory retirement rules in the French private sector. Mandatory retirement refers to specific job termination rules for older workers. Importantly, it does not mean that the employee is forced to claim a pension, but simply that the employer can dismiss the employee with much fewer restrictions than in the general case. Demand-side effects are often pinpointed as an important driver of older workers' labor force participation (see for example Lumsdaine and Mitchell, 1999; Duval, 2003). The theoretical mechanism is straightforward: with (perceived) declining productivity with age and some degree of wage rigidity, firms have incentives to lay off older workers and hire younger ones. Yet in most existing economic models, retirement is described as the result of an individual trade-off between work and leisure. ${ }^{1}$ The implicit assumption is that labor demand is infinitely elastic, and that the retirement age is chosen by workers. This focus on the supply-side dimension may be partly due to a lack of identifying variations: as employers' and employees' incentives and preferences are often aligned, demand- and supply-side effects are difficult to disentangle.

Taking advantage of a unique quasi-natural experiment, the progressive ban of mandatory retirement in the 2000s in France, I can identify an effect of the employer's decision in the retirement process. Before 2003, mandatory retirement was possible from the full retirement age, which can be reached from age 60 for individuals who have accumulated enough years of contribution. The minimum mandatory retirement age was then increased from 60 to 65 . The increase was implemented progressively over time and at different timing according to the type

\footnotetext{
${ }^{1}$ There are two main strands in the literature on retirement decision: structural models (e.g., Rust and Phelan, 1997; or French, 2005), or reduced-form estimations eliciting the main determinants of retirement decision (e.g., Coile and Gruber, 2007; or Brown, 2013). In both of them, retirement is modeled as a purely individual (or household) decision.
} 
of employer, due to industry-based specific labor market legislation in France. More precisely, the 2003 reform banned mandatory retirement before 65 in the general case, but allowed some industries to circumvent this increase through industry-based collective agreements. I use a difference-in-differences approach, comparing industries that implemented a derogatory agreement extending mandatory agreement to those industries that did not. This makes it possible to insulate this factor from other determinants of retirement - in particular financial incentives to pursued activity - that were also changed by the 2003 reform.

To explore these questions, this work relies on an extensive administrative database, provided by the Caisse nationale d'assurance vieillesse (Cnav), the public pension scheme for wage earners of the private sector. It is the largest pension scheme in France, covering two thirds of the working population. This dataset provides the employers-employees linkage required to study the interaction between labor demand and supply in the retirement process.

The paper contributes to the relatively scarce literature identifying a labor demand effect on the retirement process. It relates to the literature studying the impact of age-specific employment protection (Behaghel et al., 2008; Hakola and Uusitalo, 2005), and more directly to the papers evaluating the effect of banning mandatory retirement in the US (Neumark and Stock, 1999; Ashenfelter and Card, 2002; Adams, 2004) or in Canada (Shannon and Grierson, 2004), using state-specific changes in the legislation. As reviewed in Neumark (2003), the literature demonstrates that increasing employment protection for older workers has a positive but overall modest effect on their labor force participation. The existing literature on mandatory retirement focuses on the specific context of the North-American labor market, with reforms occurring in the 1960-1980s. Paradoxically enough, no paper has studied the effect of this type of scheme in Europe, where labor market legislation is suspected to have a strong impact on employment rates of older workers. Using cross-country variations and self-assessed retirement motives, Dorn and Sousa-Poza (2010) find that "involuntary retirement" is relatively more frequent in Europe, and pinpoint the labor market legislation as one of the key explanations. A previously uncovered component of this European specificity may be the mandatory retirement schemes, which still exist in some European countries (Austria, Italy, and Germany for some specific contracts) and were recently removed in others (Spain in 2012, UK in 2011). This paper provides robust evidence of an effect of these rules on the labor force participation of older workers for France.

In addition, this paper relates to the literature studying the bunching in retirement rates at some key ages of the social security system, namely the minimum retirement age and the full retirement age. Those spikes have been largely documented in the literature, for many different countries (Gruber and Wise, 2004). Bunching in retirement age distribution observed at the full retirement age has received many complementary explanations: social security incentives, with lower than actuarially-fair adjustment, incentives of firms private plans, or interaction with Medicare. All those explanations taken together, however, are not 
enough to explain the magnitude of the spikes, as suggested by Lumsdaine et al (1996). The residual part of the spikes that cannot be explained is usually attributed to norms or framing (Mastrobuoni, 2009; Blau and Behaghel, 2012). This paper exhibits an original demand-side determinant of the usual "puzzle" of bunching in retirement patterns: since the mandatory retirement age has coincided with the full rate age for a long time, the concentration of retirement at the latter can be partly explained by the former.

The rest of the paper proceeds as follows. In the next section, I briefly describe the institutional context regarding pension and mandatory retirement rules. Section 3 describes the French data used in this paper and presents descriptive statistics of the estimation sample. Section 4 presents the identification strategy along with the graphical analysis supporting it. Section 5 presents the effect of mandatory retirement on the employment of older workers, and section 6 focuses on the effect on bunching at full rate. Section 7 concludes.

\section{Institutional background}

\subsection{Overview of the French pension system}

The public pension system in France is large and fragmented. It consists of more than 30 different pension schemes with benefits amounting to roughly $14 \%$ of GDP. In this paper, I focus on the Régime général ( $R G)$, the main scheme for wage earners of the private sector. As France's most important public pension scheme, the $R G$ covers more than two thirds of the working population. Together with its complementary point-based public mandatory pillar, it provides the main part of income during retirement. Benefits can be claimed from the minimum age of eligibility, which is 60 for the period of interest (years 2000-2012).

Understanding the empirical strategy employed in this paper requires a decomposition of the pension benefit. The general formula for computing benefits $B$ is the following:

$$
B=W_{\text {ref }} \times C P \times \tau
$$

The pension is proportional to a reference wage $W_{\text {ref }}$, which is the average of the 25 best yearly earnings under the Social Security ceiling. It also depends on a coefficient of proportionality (coefficient de proratisation, $C P$ ) accounting for the years contributed in the pension scheme. The main parameter of interest in the analysis is the pension rate $\tau$. It corresponds to a reference replacement rate $\tau_{\text {ref }}$ of $50 \%$, which can be either increased by a bonus in case of pursued activity beyond the full rate age, or decreased by a penalty in case of early retirement before this age.

One important peculiarity of the French pension system is that reaching the full rate ${ }^{2}$ depends on both age and work duration, and not only on age, as is the case in many other

\footnotetext{
${ }^{2}$ Here, the "full rate" is defined as $\tau \geq \tau_{\text {ref }}$, that is, when the penalty cancels out.
} 
countries. The full rate age can be reached under two conditions: either an age condition, when the normal retirement age (NRA) is reached; or a work duration condition, if the insurance duration $D$ equals the full rate work duration $\left(D_{F R}\right)$. For the cohorts under study, NRA is equal to 65 , and $D_{F R}$ depends on the year of birth (which equals 160 trimesters for cohort 1943). The most favorable condition for the workers (the one that is reached first) is retained. It implies that a worker can reach the full rate as soon as she reaches the minimum age of eligibility of 60 , if she has contributed the required amount of trimesters $D_{F R}$.

\subsection{Mandatory retirement: rules and recent reforms}

Retirement decisions may interact with many labor market mechanisms that could influence workers' and firms' behavior. In the 1980s-1990s in France, successive governments implemented reforms providing incentives for early withdrawal of older workers from the labor force. The driving idea was to make room for the unemployed and younger workers entering the labor force: extension of early retirements before the standard eligibility age of 60 ; extension of unemployment benefits for older people (longer duration, less counterparts in terms of job search); and the one I focus on in this paper, simplified procedures to lay-off older workers (mise a la retraite d'office, i.e., mandatory retirement).

\subsubsection{Dismissal through mandatory retirement}

Typical long-term contracts in France can only be terminated under specific circumstances, characterizing a fair dismissal: either economic redundancies or dismissal for professional faults. Dismissal compensations associated with a fair dismissal are set by the national Labor Code, or by collective labor agreements signed at the level of the industry. When a dismissal is deemed unfair, the employer may have to pay an additional compensation. The amount of this compensation, which is determined by a Labor Court, can be high and is rather unpredictable; from the employers' point of view, therefore, it is quite risky .

The common "mandatory retirement" expression ${ }^{3}$ is somehow misleading, as it refers to labor market rules rather than pension legislation. Formally speaking, mandatory retirement can be described as a third type of fair dismissal: the employee can be dismissed without a cause, as soon as she has reached the mandatory retirement criteria, which are essentially based on age. Before 2003, firms were allowed to lay-off workers without any justification after age 60 , as soon as they reached the full rate age, either under the age or the duration condition. This rule was implemented in 1987 but was already a common practice before this date (Chaslot-Robinet, 2008). Special dismissal compensations are associated with this type of layoff, which must be at least equal to the basic compensation for fair dismissal.

\footnotetext{
${ }^{3}$ Popularized by the seminal paper of Lazear (1979).
} 


\subsubsection{A progressive increase in the mandatory retirement age}

From the early 2000s, imbalances in the pension system made it necessary to maintain older workers in the labor force. Most schemes providing incentives to retire as early as possible were progressively removed. In that vein, mandatory retirement was soon restricted with the 2003 reform. It set the minimum age for mandatory retirement at 65 instead of the previous double condition of age (60) and full rate eligibility. As a large proportion of individuals reaches the full rate at age 60 under the work duration condition, this reform amounts to an increase in the mandatory retirement age from 60 to 65 . The reform, however, was not globally implemented, as some exemptions were made possible. Some industrial branches were indeed allowed to continue on the previous scheme, if they signed a derogatory agreement before January 1st of 2008. ${ }^{4}$ Under rather light employment-related compensations (e.g., hiring one new worker for two lay offs through mandatory retirement), some industries were allowed to maintain the previous rules allowing lay-off through mandatory retirement from age 60 , provided that the worker was eligible for a full rate pension. Facing a wave of derogatory agreements, the legislator forbade any new signature in 2006, and derogatory schemes were scheduled to be closed by January 2010 .

A last reform in 2010 further increased the minimum age for mandatory retirement from 65 to 70 . In this paper, I focus on the increase from 60 to 65 of the mandatory retirement age, as for the period of interest the labor force participation beyond 65 is very small.

\subsection{Contemporaneous reforms of the pension system}

The evolution of the legislation on mandatory retirement is contemporaneous with other important reforms of the pension system.

The first of these is the implementation of a bonus for working beyond the full rate age FRA. Before the 2003 reform, there was no increase in the pension conversion rate $\tau$ once the individual had reached the required duration, $D_{\mathrm{FR}}$. The reform introduced an actuarially fair adjustment (the surcote), from January 1st of 2004. Importantly, this change in the financial incentive to work goes in the exact same direction as the repeal of mandatory retirement before 65 . Both reforms should increase the probability to work beyond the full rate. ${ }^{5}$ In the absence of derogatory agreements, it would have been impossible to disentangle between the labor demand (end of mandatory retirement) and labor supply (financial incentives) effects.

Another important element of the 2003 reform is the implementation of early retirements before the minimum retirement age (60 at the time). Those early retirements were only available for workers who have worked for a long time and have started to work early. This

\footnotetext{
${ }^{4}$ Those derogatory agreements were not mentioned in the first draft of the law, suggesting a resistance to this change, possibly from industrial lobbies. See Ciccotelli (2016) for an analysis of the role played by employers' unions in labor market policies in France since 1960.

${ }^{5}$ Benallah (2011) shows that the implementation of the surcote had a small but positive employment impact. The paper, however, does not account for the contemporaneous change in mandatory retirement legislation.
} 
reform interacts with the change in the rules for mandatory retirement. Indeed, some firms (illegally) used these early retirements to extend mandatory retirement to individuals under the age of 60 who satisfied the conditions, with potential effects on exit rate before 60 . It can also induce a selection bias on the population of interest (aged 60 to 64), since individuals still who are employed at 60, even though they could have retired earlier, may be specific.

Before presenting the identification strategy and the ways I address potential confounding biases, the next section presents the data used in the empirical analysis.

\section{$3 \quad$ Data and descriptives}

\subsection{The French Social Security administrative dataset}

To examine the impact of mandatory retirement on labor force participation, I use highly detailed administrative data from the general scheme of wage earners of the private sector (Caisse nationale d'assurance vieillesse, Cnav). The Cnav $1 / 20^{\text {th }}$ sample (thereafter Cnav sample) is a random draw of $1 / 20^{\text {th }}$ of the population affiliated to the general scheme (both workers and retirees), based on individual Social Security number.

The sample contains information on work history (from 1947 to 2012), and pension rights for retired affiliates. The initial sample contains about 2 million observations (on average, 50,000 by generation), among which $75 \%$ of workers and $25 \%$ of retirees. As it is an administrative dataset, we have only a few demographic variables: date of birth, birth location (France or abroad), and gender. On the other hand, labor market outcomes are quite detailed: the dataset contains, for each individual and for each year, the number of trimesters validated for pension computation, for each type of validation (work, unemployment, child-bearing, sick leave). Earnings are recorded for periods worked as wage earners of the private sector only. From 2000 onward, the data provides a linkage between employees' and employers' characteristics that is crucial for our identification strategy. Several firm-specific variables are available for each employment spell: geographical location, industry affiliation, and firm identifiers.

Since we do not have detailed information about work history outside the general scheme, we focus on individuals who have at last one period recorded in this scheme. As we only observe information on employers from year 2000 on, we focus on recent generations, the first being generation 1934 (or those who reach age 65 in the year 2000). Finally, since we focus on employment rates from age 60 and above, the initial sample is further restricted to individuals who are still employed in the general scheme the year they reach 60. It is a strong restriction, especially in France, where a large part of the population has already withdrawn for the labor force when reaching this age. We end up with a sample of 167,867 individuals. 


\subsection{Data on collective agreements}

As developed in the next section, our identifying source of variation is the extension of mandatory retirement after 2003, through the signature of collective industry-based derogatory agreements. This requires being able to identify whether a worker is exposed to a derogatory agreement at a given point in time.

To begin, we must gather all the derogatory agreements signed between 2003 and 2006. Using a list provided by the French Ministry of Labor, I am able to recover 69 exemptions, on a total of 91 according to administrative sources (Bur, 2007). ${ }^{6}$ The missing exemptions concern firm-level agreements for which I do not have data, as I only have access to exemptions signed at the level of the collective labor agreement.

The main difficulty is that the relevant collective labor agreement applying for a worker at a given point in time is not directly available in the Cnav data, and must be incorporated from external data. Appendix A details the matching methodology, which can be summarized as follows. I use a correspondence table between the industry code of the firm I observe and the collective labor agreement. It gives, for all industries, the percentage of workers attached to the different collective agreements. The following rule is applied: for each industry, if at least $50 \%$ of the workers are covered by a given collective agreement, we consider that all workers from this industry belong to the latter.

As a result, my main source of variation - collective labor agreements and the associated derogatory agreements - is imprecisely measured. The quality of the matching can be assessed using the latest version of the Echantillon inter-régime des retraités(EIR) ${ }^{7}$ which includes direct information on workers' collective agreement from year 2005. We apply our matching methods to the EIR sample and we can compare the true collective agreement to the imputed one. Doing so, we find that we wrongly classify only $10 \%$ of the individuals. At any rate, the misclassification of some individuals within each industry is not a main concern for identification, as it mainly induces measurement error and attenuation bias.

\subsection{Descriptive statistics}

The matching between our main dataset and the data on collective agreements creates three distinct groups of employees. Some workers are assigned to an industry that signed a derogatory agreement, while others are assigned to an industry that did not sign any derogatory agreement, and still others cannot be matched to any main collective labor agreement. ${ }^{8}$

Table 1 presents some descriptive statistics for the three groups, once the filters and the

\footnotetext{
${ }^{6}$ The list of agreements, with the associated industry, the date of signature and the date of implementation is reported in Appendix B.

${ }^{7} \mathrm{EIR}$ is a panel of retirees with administrative career record in most existing pension schemes. See Mahieu and Blanchet (2004) for a detailed presentation of the data.

${ }^{8}$ This final case occurs either when no collective agreement represents more than $50 \%$ in this industry, or when information is not available in the correspondence table.
} 
matching methodology described in the previous two subsections are applied. The first two groups form the sample used for the empirical analyses.They are of equal size, and amount to around half of the initial sample. They differ significantly, however, in their composition. Individuals working in industries that implemented a derogatory agreement are relatively more often men (30\% vs. $46 \%$ of women), have started to work younger, and have validated more trimesters for retirement when they reach 60 (around 2 and a half years). Average annual earning at 60 is also much higher $(19,644 €$ vs. $16,813 €$ for men). For a sub-population of retirees, descriptive statistics can be enriched with the comparison on retirement outcomes. On average, individuals working in firms for which I imputed a derogatory agreement retire younger and with a higher pension. This stems from the fact that they have higher earnings and insurance duration, both variables positively correlated with the level of benefits.

Table 1: Descriptive statistics for the sample of affiliates

\begin{tabular}{|c|c|c|c|}
\hline & $\begin{array}{c}\text { Industries } \\
\text { with DA }\end{array}$ & $\begin{array}{c}\text { Industries } \\
\text { without DA }\end{array}$ & $\begin{array}{l}\text { Unmatched } \\
\text { industries }\end{array}$ \\
\hline \multicolumn{4}{|l|}{ Sample size } \\
\hline $\mathrm{Nb}$ indiv & 47,013 & 34,749 & 67,352 \\
\hline$\%$ of initial sample & 0.33 & 0.24 & 0.47 \\
\hline \multicolumn{4}{|l|}{ Demographics } \\
\hline Proportion of women & 0.30 & 0.46 & 0.57 \\
\hline Proportion born in France & 0.77 & 0.76 & 0.81 \\
\hline \multicolumn{4}{|l|}{ Career } \\
\hline Mean age at LF entrance & 18.9 & 19.6 & 19.7 \\
\hline Mean insurance duration at 60 (men) & 154 & 143 & 141 \\
\hline Mean insurance duration at 60 (women) & 156 & 140 & 146 \\
\hline Annual gross earnings at 60 (men) & 19,644 & 16,813 & 18,931 \\
\hline Annual gross earnings at 60 (women) & 17,232 & 13,601 & 15,579 \\
\hline \multicolumn{4}{|l|}{ Pension claims (cohort <1948) } \\
\hline Mean claiming age & 61.53 & 61.93 & 62.17 \\
\hline Mean retirement age & 61.38 & 61.67 & 61.88 \\
\hline Mean annual pension benefits & 12044 & 9520 & 9940 \\
\hline \multicolumn{4}{|l|}{ Main sectors of activity } \\
\hline $1^{\text {st }}$ largest sector ( $\%$ of the group) & Manufacturing (32\%) & Trade $(20 \%)$ & Health and social work (27\%) \\
\hline $2^{\text {nd }}$ largest sector ( $\%$ of the group) & Construction $(23 \%)$ & Transportation (15\%) & Public administration (22\%) \\
\hline $3^{r d}$ largest sector ( $\%$ of the group) & Technical activity $(10 \%)$ & Food $(15 \%)$ & Trade $(9 \%)$ \\
\hline $4^{t h}$ largest sector ( $\%$ of the group) & Finance $(9 \%)$ & Public services (14\%) & Private services $(8 \%)$ \\
\hline $5^{t h}$ largest sector ( $\%$ of the group) & Public services $(6 \%)$ & Manufacturing (12\%) & Public services $(7 \%)$ \\
\hline
\end{tabular}

SOURCE: Cnav 1/20 th sample.

NotE: The table presents descriptive statistics for three groups: individuals working in industries that signed a derogatory agreement, individuals working in industries that did not, and individuals working industries to which we cannot assign a collective agreement.

Those differences in the observable between the groups reflect the fact that derogatory agreements were not signed randomly among industries. Two main sectors, "Manufacturing" 
and "Construction", represent half of the group of industries with an exemption, and only $10 \%$ of the group of industries without. Conversely, this latter group is over-represented among trade, transportation, or food industries. Finally, the main industries that I am not able to match belong mostly to semi-public sectors (such as "Public administration" or "Health and social work"), due to the fact that information on collective labor agreements for the corresponding employers is not publicly provided.

The fact that the groups of industries with and without a derogatory agreement are different was expected. This is not crucial for my main identification strategy, which relies on a differences-in-differences approach. I discuss the potential violations of the common trend assumption in the following section. The specificity of the unmatched sample is a concern only for external validity.

\section{Empirical strategy}

\subsection{The difference-in-differences setting}

In this section, I present the empirical strategy for the identification of the effect of mandatory retirement on labor force participation of older workers. The main reform of interest is the 2003 pension reform that banned mandatory retirement before the age of 65 in the general case. The expected effect of the reform is an increase in the labor force participation for individuals aged 60 to 64 , as some workers who would have been forced to retire through mandatory retirement can keep on working beyond the full rate work duration. A simple before/after analysis is not possible in this case, because of at least two potential confounding factors. First of all, there are important trends in labor force participation as well as sensible changes in the macroeconomic business cycle around the period under study. Secondly, in addition to the change regarding mandatory retirement, the 2003 reform also implemented a pension bonus for continued work beyond the full rate (surcote), one that did not exist before. The expected effect of this surcote goes in the same direction as banning mandatory retirement. ${ }^{9}$ Identifying the effect of mandatory retirement consequently requires an additional source of variation.

The empirical strategy then relies on the industry-specific timing of the demand-side aspect of the 2003 reform to identify a causal effect of mandatory retirement on the labor force participation of older workers. As described in section 2, some industries were exempted from the 2003 reform and were allowed retain the previous rules for mandatory retirement. Those exemptions are used as the identifying variations of the effect of mandatory retirement, using a difference-in-differences strategy.

Recall that mandatory retirement was possible from age 60 , provided that the worker was

\footnotetext{
${ }^{9}$ The general idea of the reform was to foster labor force participation at older ages, and thus played on both labor demand and labor supply sides.
} 
eligible for a full rate pension. The treatment variable will then be defined according to those exemptions, the treated group $(\mathrm{T})$ being the industries that signed a derogatory agreement, and the control group (C)being those that did not. Since all the exemptions are canceled from January of 2010, the treatment status of the control and treatment groups only differs between 2004 and 2009. In parallel, the financial incentives to work beyond the full rate were reinforced uniformly in both groups: from 2004, a bonus was implemented, increasing the pension conversion rate for trimesters worked beyond the full rate duration $D_{F R}$.

As summarized in Table 2, for individuals eligible for a full rate pension, we start from a situation with very low demand and supply side incentives to work and end up in a situation with increased incentives on both sides. The identification of the causal effect of mandatory retirement stems from the time window in which demand and supply-side incentives are not aligned, when the derogatory agreements are in place. The difference-in-differences analysis then compares the evolution of the employment of older workers in industries with and without a derogatory agreement extending mandatory retirement before 65 . I only use the pre- and post-reform periods to identify the effect of mandatory retirement. The post-treatment period, however, offers a valuable ex post placebo test for the parallel trend assumption, at the heart of the difference-in-differences strategy.

Table 2: Summary of the empirical strategy Reforms of mandatory retirement (MR) and financial incentives (FI)

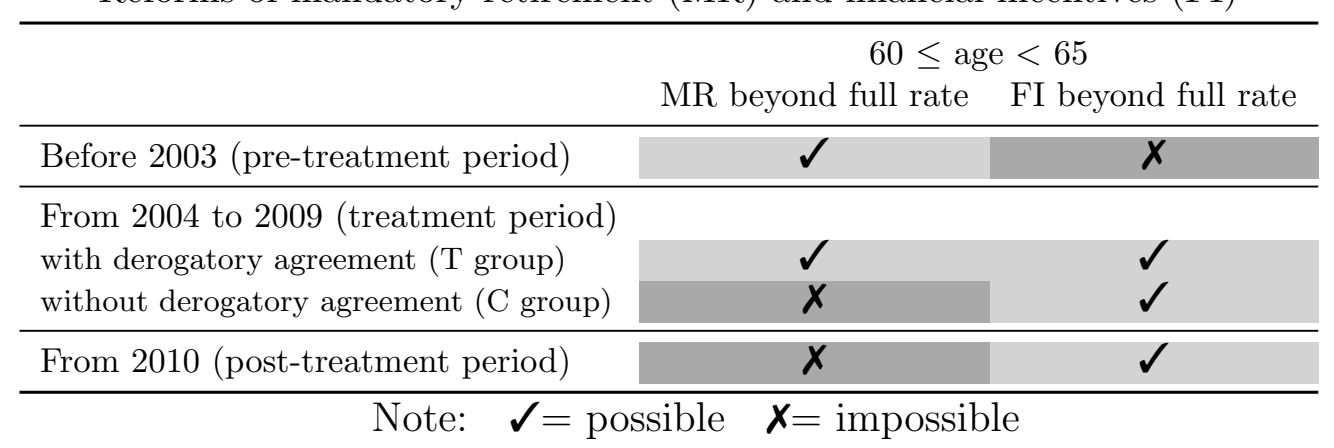

The empirical analysis relies on the hypothesis that the differential evolution observed for the treated and control group is only driven by the mandatory retirement rules. This assumption can appear as strong, on two grounds. Firstly, derogatory agreements have been signed in specific industries that may be exposed to specific macroeconomic shocks. It is all the more possible since the treatment years overlap with the late 2000s macroeconomic crisis. For example, one could think that industries that signed a derogatory agreement were also more severely touched by the crisis, and would have had a stronger turnover even in the absence of derogatory agreement. Secondly, the exogeneity of the treatment can be questioned, as it is likely that the ratification of a derogatory agreement is correlated with other industry-level determinants of labor force participation of older workers. Derogatory agreements could be 
correlated with some demand-side determinants of retirement, as industries that decided to retain the former mandatory retirement scheme were plausibly more willing to use it. We could also imagine a positive correlation between the derogatory agreement and some determinants of labor supply, for example preference for leisure. ${ }^{10}$ I discuss at length those potential threats to identification and their consequences regarding internal and external validity in section 5 . In particular, the graphical evidence provided in subsection 5.1 makes a rather convincing case for the parallel trend assumption and the identification of a causal impact of mandatory retirement.

\subsection{Econometric specification}

We adopt a classic difference-in-differences specification, with time and group fixed effects and a treatment dummy.

$$
Y_{i, j, t}=\alpha+\lambda_{t}+\mu_{j}+\delta \mathrm{T}_{j, t}+\beta_{X} X_{i, j, t}+\epsilon_{i, j, t}
$$

with :

$$
\left\{\begin{aligned}
Y_{i, j, t} & : \text { Labor market outcome } \\
\lambda_{t} & : \text { Time dummy } \\
\mu_{j} & : \text { Industry dummy } \\
\mathrm{T}_{j, t} & : \text { Treatment dummy } \\
X_{i, j, t} & : \text { Controls }
\end{aligned}\right.
$$

The main explanatory treatment variable $T_{j, t}$ refers to the ratification of the derogatory agreements. It depends on both time and industry: it is equal to 0 for everybody before 2003, to 0 or 1 afterwards depending on whether a derogatory agreement is in place to the given industry, and to 0 for everybody from 2010, when the exemptions are repealed. Controls include age dummies, gender dummy, age of entrance in the labor market, and a dummy for being born in France.

Different dependent variables $Y_{i, j, t}$ could be considered. The most usual ones in the literature are retirement (definitive withdrawal from the labor force) or benefits claiming. They may not be the most relevant for this specification for both theoretical and practical reasons. As explained in section 2, mandatory retirement does not formally correspond to a forced retirement, but to a layoff. It implies that a worker can theoretically find another job after he was laid off through mandatory retirement. So mandatory retirement can occur before benefit claiming and even withdrawal from the labor force.It is all the more problematic since we observe recent generations that are not entirely retired in our dataset, so that if we observe a worker losing her job in the most recent years of observation we cannot tell if she has withdrawn from the labor force or not. I thus fall back on a more general labor market

\footnotetext{
${ }^{10}$ The fact that important workers' unions, in many cases, also signed the agreement goes in that direction.
} 
outcome for the main explained variable: job exit. $Y_{i, j, t}$ is equal to one if the individual $i$ works in industry $j$ at time $t$ but no longer at date $t+1$ (with either a transition to another industry or not).

As previously mentioned, mandatory retirement before 65 is only possible when the worker is eligible for a full rate pension, which is when she has validated at least the required number of trimesters, $D_{\mathrm{FR}}$. This provides another potential source of identification of the effect of mandatory retirement: only individuals with the required duration $D_{\mathrm{FR}}$ can be impacted by the 2003 reform and the following derogatory agreements. A natural extension of the previous empirical strategy is then to introduce the full rate variable in the main specification in a triple differences framework.

Unfortunately, it is impossible to precisely locate the full rate in our main dataset. The career history is not well reported before pension claiming, the moment the administration needs to have complete information in order to compute the benefits. For example, the number of children for women and some periods worked in other pension schemes are not always reported before claiming. It implies that we are unable to know exactly how many trimesters a given worker has validated at a given age. Hence, before retirement, we cannot know for sure if an individual is working beyond her full rate or not.

The first possibility, which will be adopted in the heterogeneity tests (subsection 5.4), is to restrict our sample to a sub-population for which the full rate age can be less imprecisely identified (men), but this comes at the cost of reduced sample size and selection. Another solution is to focus on a population of retirees, for which we have a complete career record. I then focus on individuals of cohorts born before 1948, who can be considered as fully retired in our sample (cohort 1948 reaches 65 in 2013). This approach also reduces the sample size but offers some compensatory features. As I have information on the whole career including retirement, I can include controls for pension level and financial incentives to retire.

Using a more tractable two-periods/two-groups approach, we consider the following model:

$$
\begin{aligned}
Y_{i, j, t}= & \lambda_{0}+\lambda X_{i, j, t}+\mu_{j}+\alpha_{1} \text { Post }+\alpha_{2} \mathrm{~T}_{j, t}+\alpha_{3} \mathrm{FR}_{i, t} \\
& +\beta_{1} \text { Post } \times \mathrm{T}_{j, t}+\beta_{2} \text { Post } \times \mathrm{FR}_{i, t}+\beta_{3} \mathrm{FR}_{i, t} \times \mathrm{T}_{j, t} \\
& +\delta \text { Post } \times \mathrm{T}_{j, t} \times \mathrm{FR}_{i, t}
\end{aligned}
$$

with :

$$
\left\{\begin{aligned}
Y_{i, j, t}: & \text { Labor market outcome } \\
X_{i, j, t} & \text { Controls } \\
\mu_{j} & : \text { Industry dummy } \\
\text { Post }: & \text { Dummy }=1 \text { after } 2005 \\
\mathrm{~T}_{j, t}: & \text { Dummy }=1 \text { when a derogatory agreement applies } \\
\mathrm{FR}_{i, t}: & \text { Dummy }=1 \text { if the full rate has been reached }
\end{aligned}\right.
$$

We expect the $\delta$ coefficient to be positive, since it gives the effect of the double treatment of being at the full rate in an industry in which mandatory retirement at full rate is still possible. We also expect the $\beta_{1}$ coefficient to be zero, as mandatory retirement should only 
impact job exit when the full rate is reached.

The triple-differences specification provides an additional test for the robustness of the results, as it tests that the effect we estimate is concentrated on individuals eligible for a full rate pension. It also gives the opportunity to study the contribution of mandatory retirement to the bunching at full rate observed in retirement behaviors. The results of the estimation of model (2) are presented in section 6 .

\section{Results}

\subsection{Graphical evidence}

Figure 1 presents graphical evidence of the causal effect of mandatory retirement on the employment of older workers. It shows the evolution between 2000 and 2011 of the average exit rate out of employment (the probability that a worker will leave her current job from one year to the other), for industries that signed a derogatory agreement ( $\mathrm{T}$ group) and industries that did not ( $\mathrm{C}$ group). We expect the job exit rate to decrease when (supply- or demand-side) incentives to work are reinforced, as workers may stay longer in employment.

The first thing to underline is the rather parallel trajectory we observe for the job exit rate for the control and treatment group in the pre-treatment years (2000-2003), and during the first years in which the derogatory agreement are signed (2004-2005). Then, from the mid 2000 s, the two curves clearly diverge when derogatory agreements are implemented. Between 2006 and 2010, the exit rate decreases by around 10pp for the control group, in industries where mandatory retirement is banned. This can be interpreted as follows: when allowed to do so, at least some workers decide to work longer. This is at least partly the effect of the increase in financial incentives to work provided by the implementation of actuarial adjustments in the pension formula. The exit rate, however, remains stable where mandatory retirement is maintained in the treatment group. It suggests that mandatory retirement has prevented the increase in older workers' labor force participation.

This interpretation is, however, only valid under the common trend hypothesis. As previously mentioned, two potentially confounding factors - the exposure to different macro shocks and the endogeneity of the treatment - question the validity of this assumption. Those doubts are partly dispelled by the evolution of the job exit rates in the post-treatment period, in the last part of Figure 1. In 2010, when mandatory retirement before 65 is not possible anymore, exit rates immediately declined in the previously treated group, without any change in trend for the control group. The rapid decline after mandatory retirement was banned makes a strong case for a causal impact of mandatory retirement over labor market participation of older workers. Indeed, this suggests that the difference in mandatory retirement rules are the main driver of the differential evolution observed for the treatment and control group. Macroeconomic shocks do not seem to be an important omitted variable. This question will 
Figure 1: Exit rate out of employment by year (between 60 and 64 ) Treatment (derogatory agreement) vs. Control (no derogatory agreement)

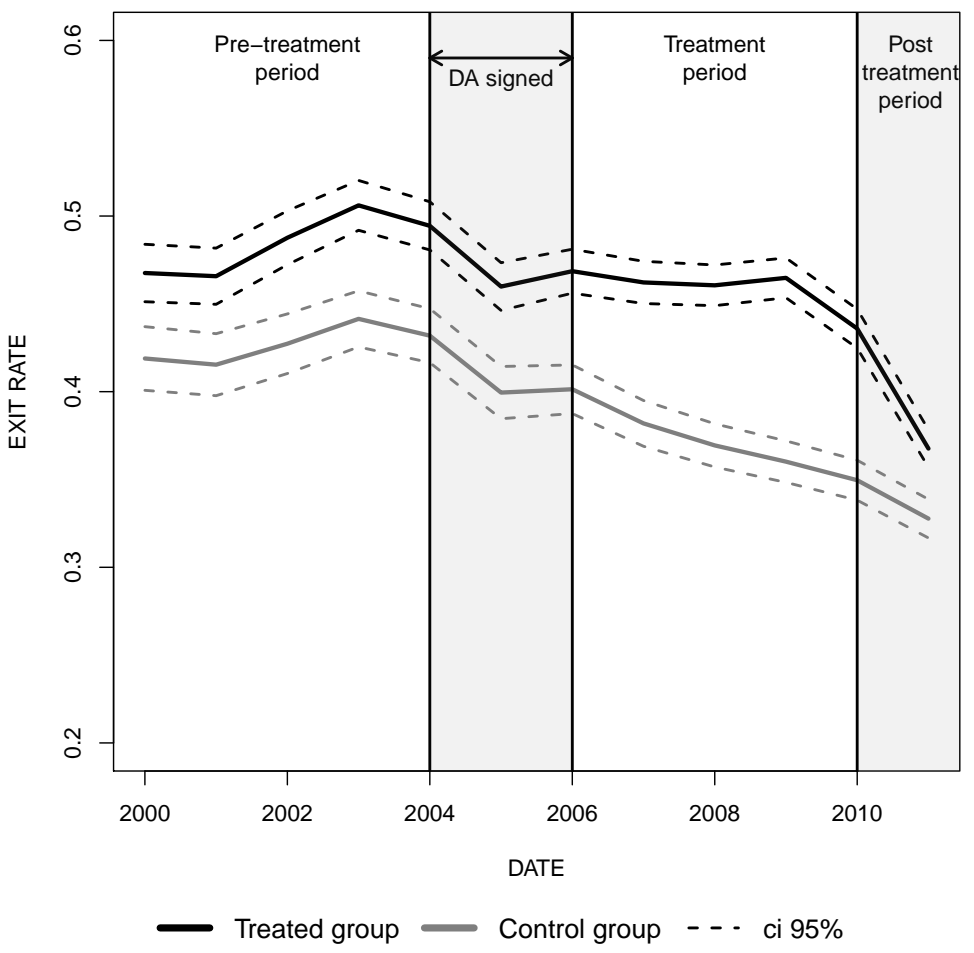

SOURCE: Cnav 1/20 th sample.

NotE: Treatment status depends on the derogatory agreement: individuals working in an industry that signed a derogatory agreement are in the treated group. Nobody is treated before 2004 (pretreatment period). Agreements are signed between 2004 and 2006, which corresponds to the first shaded area (DA signed). Between 2006 and 2010, the treated group is treated, whereas the control group is not (treatment period). From 2010, derogatory agreements are canceled and, once again, neither the treatment nor the control is treated (post-treatment period).

be further examined in the robustness tests of subsection 5.3. This pattern also makes the identifying parallel trend assumption more likely to hold, as the difference in outcome between the treated and control groups goes back to its initial level, once the treatment is removed. This is illustrated in Figure 2, which reproduces the evolution of Figure 1 with year 2000 as a reference. In other words, it suggests that, absent the derogatory agreements, workers of both groups would have behaved similarly. We will thus consider that potential biases arising from the supply-side endogenetiy of the treatment are plausibly weak. The consequences of the potential demand-side endogeneity of the treatment regarding external validity are discussed in more details in the next sub-section. 
Figure 2: Exit rate out of employment by years (base $=1$ in year 2000) Treatment (derogatory agreement) vs. Control (no derogatory agreement)

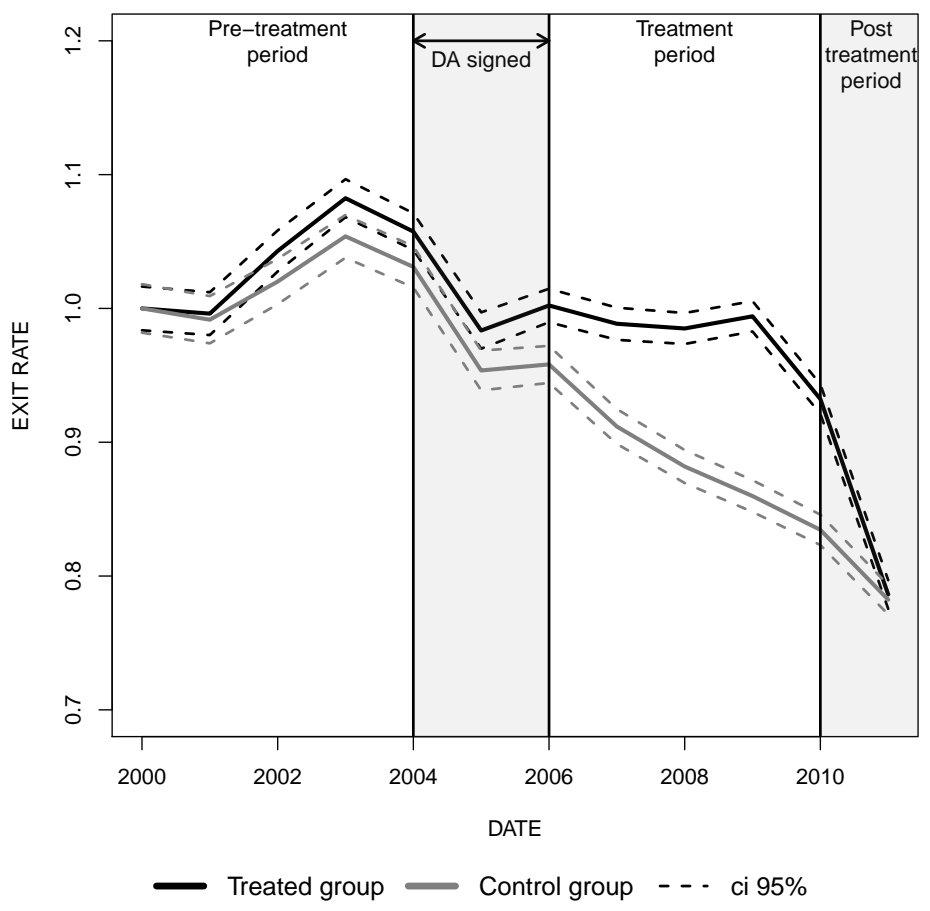

Source: Cnav $1 / 20^{\text {th }}$ sample

Note: See Figure 1.

\subsection{Main results}

Table 3 presents the main results of the empirical analyses presented in the previous subsection. All models are estimated by OLS. ${ }^{11}$ In the first two columns, time and industries dimensions are collapsed in a two-period/two-group setting: before 2003 and after 2005, when most of the derogatory agreements are implemented, ${ }^{12}$ and industries with or without agreement. This specification provides useful baseline estimates for the level of job exit rates in both groups prior to the reform, and for the trend of the non-treated group. The latter gives, by assumption, the counterfactual trend of the treated group without derogatory agreements. As already shown in Figure 1, exit rates are higher in the treated group, by $3.6 \mathrm{pp}$ according to the estimate, once accounted for differences in observables (column 2). For the control group, the exit rate decreases by $5.4 \mathrm{pp}$, which is interpreted as the effect of the reform increasing financial incentives to work. Finally, we find a significant effect for the interaction term between the time and treatment variables, which is positive as expected, since the derogatory agreement should increase the probability of job exit through mandatory retirement.

\footnotetext{
${ }^{11}$ Results are similar with a non-linear model estimation such as probit.

${ }^{12}$ Years 2004 and 2005 are dropped from the main sample in this specification.
} 
The estimated effect of the derogatory agreement in the two period/two group specification is of the expected sign (positive) and significant at the $5 \%$ level. The point estimate $(+2.8 p p)$ is close to the one found in the following columns, presenting the results of regression equation (1), without controls (column 3) and with controls (columns 4-5). Standard errors are clusterized at the industry and year level to account for potential specific shocks (column 5 ). To deal with the possible issue of autocorrelation within groups raised by Bertrand et al. (2004), we also compute standard errors clustered at the level of the industries only, in column 4 of Table 3). Here lies my preferred specification, which will be used as a reference for the robustness and heterogeneity tests in the next subsections.

The last column of Table 3 tests whether I can detect a difference in the evolution of the treated and non-treated industries when I exclude the years for which the derogatory agreements were in place (2004-2009). Indeed, the rapid repeal of the agreements in 2010 provides quite a valuable ex post placebo test. Estimates gives a near-zero and insignificant effect for the treatment. This confirms the visual impression of Figure 1, in which the job exit rate rapidly converges towards its counterfactual trend in the absence of reform. This gives considerable credit to the parallel trend hypothesis at the heart of our identification strategy.

\subsubsection{Magnitude and interpretation}

From our main specification, mandatory retirement is estimated to increase the yearly probability of exit from employment of workers aged $60-64$ by 2.3 percentage points. Compared to a baseline of $38 \%$ yearly job exit rate in the control group before the reform, it implies that workers of a firm allowing mandatory retirement are $6 \%$ more likely to exit employment compared to workers who cannot be forced to retire before 65 . The magnitude of the effect is similar to the ones found in Adams (2004) or Neumark and Stock (1999). ${ }^{13}$

This magnitude of the effect seems small on an aggregate level. If we consider that (i) every exit is permanent, (ii) that there is no adverse effect of banning mandatory retirement on hiring, (iii) that there are around 750,000 workers in the private sector aged $60-64$, and (iv) that derogatory agreements affects $33 \%$ of them (as estimated in our sample, cf. Table 1), then a $6 \%$ jump in the exit rate with mandatory retirement corresponds to around 15,000 employment terminations every year between 2005 and 2009. Hence we can conclude that the derogatory agreements did not have a huge impact on the evolution of the overall labor force participation of older workers.

The effect is sizeable, however, if we compare it to the counterfactual decrease in exit rate in the absence of reform, given by the trend observed for the control group. From the estimates of the the two periods-two groups specification, we can see that the positive effect of derogatory agreement on job exit $(+2.8 p p)$ significantly curbs the counterfactual

\footnotetext{
${ }^{13}$ Adams (2004) estimates an increase of $2.75 \mathrm{pp}$ in employment for the concerned population (age 50 and above), corresponding to a $4.45 \%$ increase compared to the baseline rate. The estimated effect is slightly smaller in Neumark and Stock (1999), around 1.7pp.
} 
Table 3: Effect of extented mandatory retirement: main results

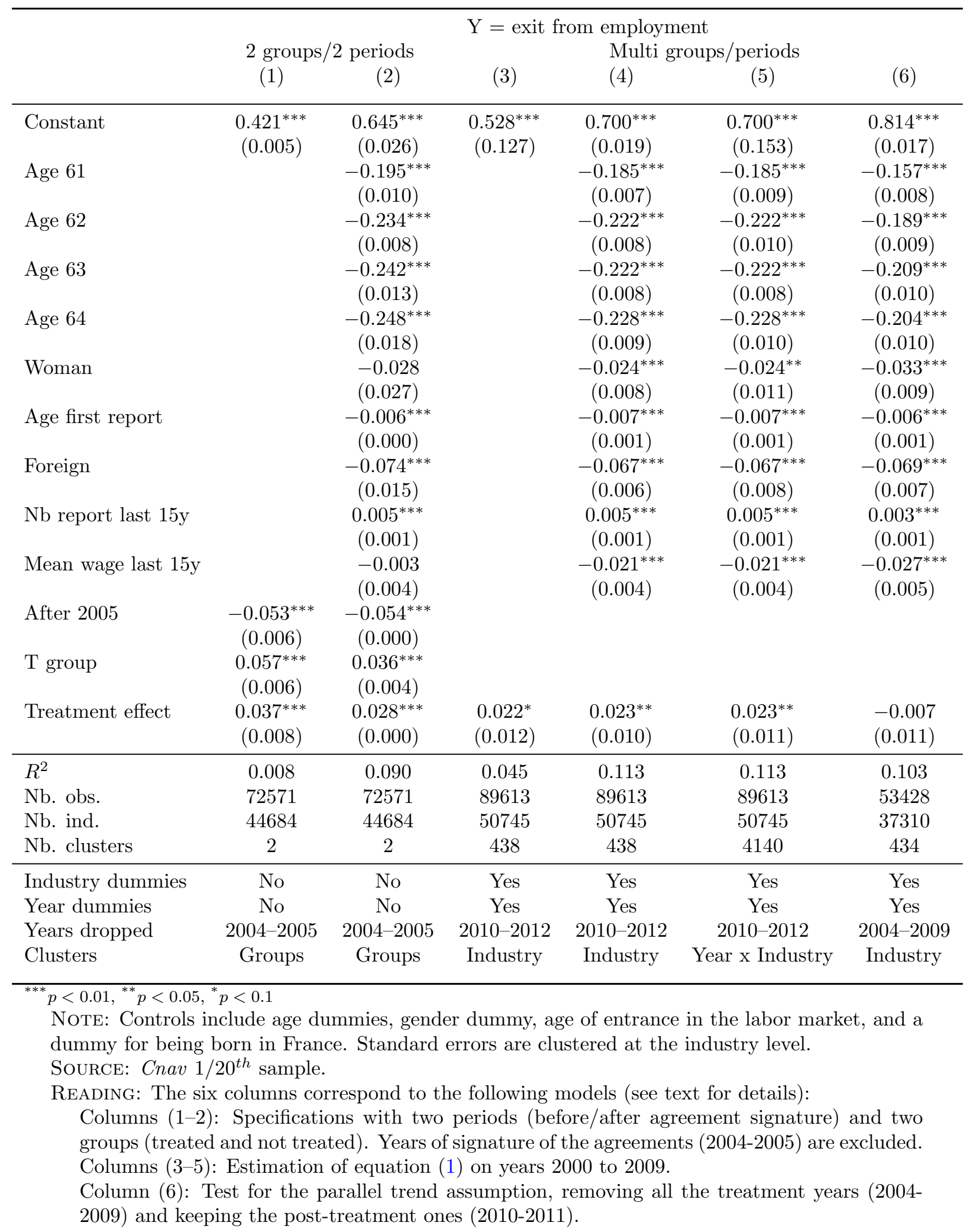


decrease over the period $(-5.4 p p)$. Derogatory agreements then reduce by nearly $50 \%$ the decrease in exit rate that we would have observed absent the reform. The decrease in exit rates observed in the control group is interpreted as being mainly the consequences of the fostering of financial incentives to work beyond the full rate, that are implemented in 2004 and reinforced in the following years. The rather small effect of the surcote on retirement behavior we observe is consistent with the evaluation of the scheme that was undertaken on the same data we use (Benallah, 2011). Assuming that the surcote is the main driver of the observed trend in job exit, our estimate suggests that its effect has been divided by two for the treated group. This can be reformulated as follows: when constraints on the demand side are not relieved, increasing financial incentives to work is not very effective at increasing the labor force participation of older workers.

Theoretically, the negative impact of the derogatory agreement on employment of older workers could be counterbalanced by a positive effect on hiring. The exemptions agreement can be seen as an decrease in job protection for the treated group, relatively to the control group. Classically, a decrease in job protection can have two effects on the targeted population: (i) an increase in the exit rates, as dismissal is easier; and (ii) an increase in hiring rates, since firms may be more willing to hire if the decision is less irreversible (Behaghel et al., 2008). Figure 3 presents the evolution of hiring rates in the treated and control industries, for individuals aged 50 to 59. If derogatory agreements were to have an impact on hiring, we would see a differential evolution between the two groups, as it is the case for exit rates. We do not find any evidence of divergence, from which we infer that, at least in the short run, counterbalancing effects on hiring are of second order of magnitude.

\subsubsection{Dynamics of the effect}

The interpretation of the results can be supported by the analysis of the dynamics of the effect of the treatment. We estimate the following model, which corresponds to the the initial one enriched with leads and lags dummies around the treatment date, as in Autor (2003).

$$
Y_{i, j, t}=\alpha+\lambda_{t}+\mu_{j}+\sum_{\tau=1}^{3} \boldsymbol{\delta}_{-\tau} \mathrm{DA}_{j, t-\tau}+\sum_{\tau=0}^{3} \boldsymbol{\delta}_{\tau} \mathrm{DA}_{j, t+\tau}+\beta_{X} X_{i, j, t}+\epsilon_{i, j, t}
$$

The interest of this specification is twofold. Firstly, it is a way to check that there is no reverse causality between the outcome variable and the treatment (if coefficients for the lags are not significant). Secondly, the leads can provide insights on the dynamics of the effect. Point estimates of $\delta s$ coefficients are reported in Figure 4, along with their $10 \%$ confidence interval. Reassuringly, there is no significant effect for the years preceding the agreement. Regarding the dynamics of the treatment, the effect is increasing with time, and is much stronger from the third year after the signature of the derogatory agreement. The removal of the labor demand constraint does not seem to have a strong instantaneous effect (insignificant for the year of the signature), suggesting that it was not binding on workers' choices. Time 
passing, labor supply adapts to the changes in financial incentives: workers are more and more willing to work beyond their full rate. Firms' and workers' choices are then more likely to be antagonistic, and mandatory retirement starts to play a role.

Figure 3: Hiring rates for those aged 50-59: Treatment vs. Control

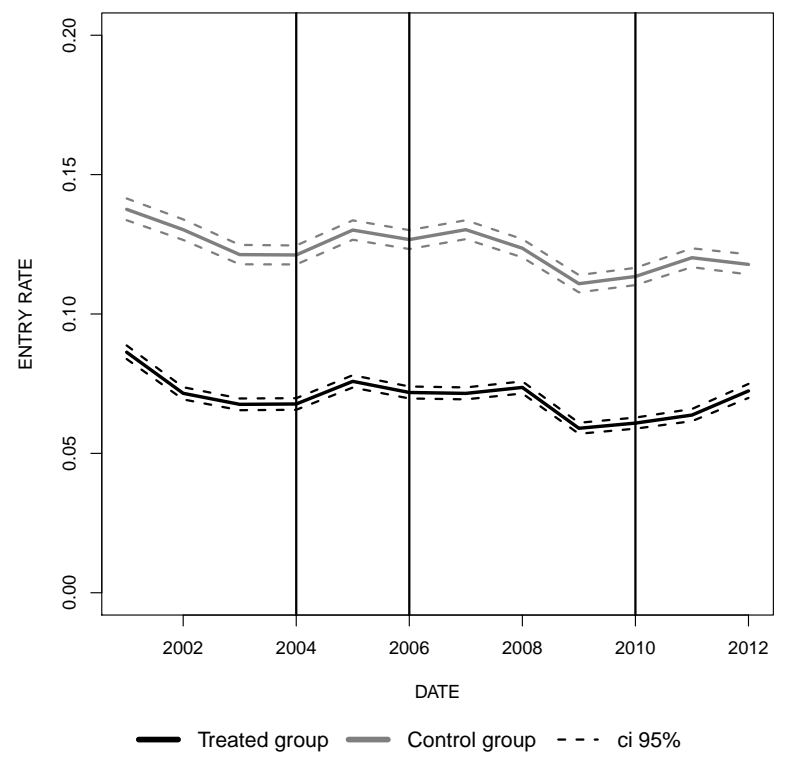

SOURCE: Cnav 1/20 th sample

Figure 4: Estimated impact of mandatory retirement extension on exit rate for years before, during, and after the signature of the extension agreement

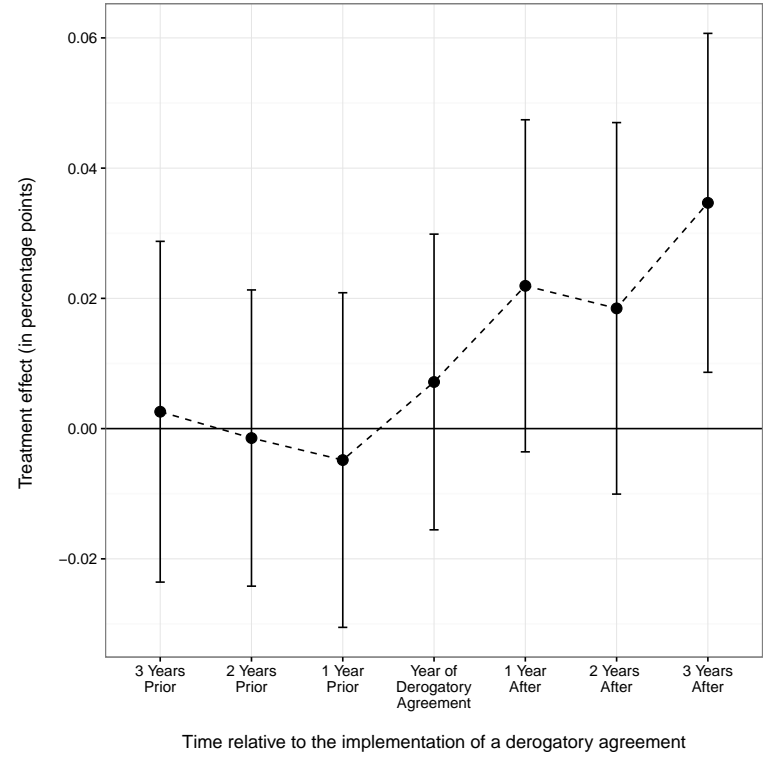

SOURCE: Cnav $1 / 20^{\text {th }}$ sample

Note: The figure presents the $\delta s$ coefficients of equation (3), with the $10 \%$ confidence intervals (with standard errors clustered at the industry level). 


\subsubsection{External validity}

As a thought experiment, we can also use our estimates to address the following question: How would exit rates have evolved if mandatory retirement has been maintained in every industry? This question is similar to asking what has been the overall effect of banning mandatory retirement for industries that did not implement a derogatory agreement. If the estimated effect corresponds to the average effect of mandatory retirement in the whole population, ${ }^{14}$ then we can compute the overall effect of the repeal of mandatory retirement using our point estimate. Under the hypothesis homogeneous effect of mandatory retirement on the treated and the control group, we could say that banning mandatory retirement doubled the increase in employment of workers aged 60-64 (or more precisely, that their job exit rate would have been twice as low had mandatory retirement been extended beyond 2003 for everybody). This hypothesis seems, however, quite strong. As previously discussed, our treatment is likely to be endogenous as derogatory agreements are not randomly signed and may be more likely to be implemented in industries where (i) workers are more willing to sign it, perhaps reflecting a lower attachment to the labor force; and (ii) employers are more willing to fire older workers through mandatory retirement. As previously commented, Figure 1 provided reassuring evidence regarding the first point: once mandatory retirement is banned, workers of the treated group converge towards the exit rates they would have had following the control group's trend. It then suggests that workers' labor supply is not very different in both groups, and that the observed divergence in exit rates is mostly driven by labor demand. This also suggests that most of the endogeneity of the treatment comes from the employers' side. In turn, this implies that the homogeneous effect assumption is quite strong: it is likely that industries that did not try to implement mandatory retirement had a lesser need for it, and would have made less use of it even if they could. The usual trade-off between identification and external validity is then particularly acute here: the supply-side exogeneity of the treatment, required for identification, seems plausible, but only comes at the cost of undermined external validity, as employers are all the more likely to self select into the treatment. Consequently, our estimates provide an upper bound of the overall effect of banning mandatory retirement in all industries.

Finally, note that it is not possible to quantify, from our results, how much mandatory retirement contributed to the decrease in labor force participation observed in the 19801990 s, before the round of reforms under study. We indeed measure the effect of mandatory retirement when workers have some incentives to work beyond the full rate, as is the case from 2004 on. The positive effect we find suggests that at least some workers would have liked to work and benefit from a pension bonus. This does not mean that before the 2003 reform, mandatory retirement had an impact. One could argue that without any incentive to work

\footnotetext{
${ }^{14}$ I.e., that the average treatment, effect on the treated $A T T$ is equal to the average treatment effect of the population ATE.
} 
beyond the full rate the effect of mandatory retirement was only marginal. In any case, it is not possible to identify a specific effect of mandatory retirement before 2003 since workers' and firms' incentives were aligned. Reciprocally, in the absence of derogatory agreements, it would not have been straightforward to disentangle between the demand and the supply sides, as the 2003 reform impacted both dimensions in the same direction.

\subsection{Robustness tests}

In this subsection, we test the sensitivity of our results through a whole set of robustness checks. We successively describe the rationale for those alternative specifications and the results they yield, which are regrouped in Table 4, and compared to the reference (column 4 of Table 3, which is reproduced in the first column here). In the previous subsection, we discussed the different kinds of endogeneity that the ratification of the derogatory agreements can embed, and their consequences regarding identification and interpretation. Even if the following tests do not all directly deal with this issue, the stability of the results through all the variants implemented is overall reassuring.

A first potential concern can be raised about the specificity of the treated group, and the omitted variable bias it could entail. Aside from the issue of the endogeneity of the treatment, the peculiarity of the treated group might be an issue if it increases the possibility that it was differently impacted by other time-varying determinants of labor force participation, in particular macroeconomic shocks. As shown in Table 1 of section 3, treated and untreated industries belong to distinct economic sectors. Consequently, they might be exposed to differential economic shocks, which could partly drive the divergence of job exit rates observed from 2003. Two robustness tests are implemented to deal with this potential issue. We first add interaction terms between the economic sector and the current years to the main specification, in order to control for intra-sector shocks. We then restrict our main sample to economic sectors in which there are both treated and untreated industries. The treatment and control groups are thus more similar and more likely to be exposed to symmetric shocks. The estimated impacts of the treatment under those two specifications are reported in columns (2) and (3) of Table 4. Reassuringly, the point estimate is still positive and statistically significant with these specifications, and of similar magnitude as in the reference. We may also fear that the results are driven by one or two very big specific industries. To test for that, we successively remove every collective agreement from the main sample and re-estimate the main model without the concerned industries. Results are robust to this exercise, as illustrated in the fourth column of the table, which presents the estimate of the main model once we have removed the biggest collective agreement (metal industry).

The second source of concern about the robustness of results presented above lies in the measurement issue regarding the treatment variable. As described in section 3.2, we do not directly observe the relevant collective labor agreement for a given worker, but only the 
percentage of workers belonging to each collective agreement within each industry. We match it with the following rule of thumb: if at least $50 \%$ of the workers in an industry belong to a collective agreement, this agreement and the related treatment status are attributed to the whole industry. Industries we are not able to match to a collective agreement (either because information is missing or the $50 \%$ threshold is not reached) are dropped from the sample of estimation. Obviously, we do not want the result to depend on the arbitrariness of this matching methodology. A first type of test verifies the stability of the result to alternative but similar methodology by changing, for example, the attribution threshold. Several tests of this type are implemented in Appendix A, and Table 4 presents the result of the main specification with a $65 \%$ threshold (column 5 ). Overall, results are quite stable to variation in the matching process.

Another strategy can be used to deal with both the threshold issue and the selection issue for that industries we are not able to match. Instead of using a binary treatment variable, we can use a continuous treatment intensity in our difference-in-differences specification, as in Acemoglu et al. (2004). Treatment intensity is defined as the percentage of workers, at the industry level, belonging to a collective agreement that signed a derogatory agreement. Since there can be more than one derogatory agreement for a given industry, potentially signed at different dates, we use a two periods specification (as in the first two columns of Table 3). The point estimate is still significant and positive, and close to the reference one (column 6 of Table 4). This suggests that neither the arbitrariness of the threshold, nor the removal of unmatched industries in the main specification, are a major issue.

Finally, as mentioned in section 2, during the period we cover another important reform of the pension system was implemented. It allowed early retirement before the minimum claiming age of 60 , under condition of work duration and early entrance in the labor market. This does not directly affect our population of interest since it impacts employment before age 60. It could however bias our estimation through a selection process of workers still in employment at 60: a bias could arise if the treated and the control groups are differentially impacted by the reform. This is likely to be the case since the two groups differ regarding the main variables determining access to early retirement, as shown in Table 1 . The expected direction of the bias is not straightforward though. Workers of the treated group are more likely to be eligible for early retirement (lower average age of first report, higher average insurance duration are 60), so that we can think that more workers of the treated group would exit employment through early retirement. If any, we could then expect a negative bias on our estimation, since early retirement relatively reduced the need for firms of the treated group to dismiss older workers. To control for this potential bias, I estimate the model on a sub-sample of individuals who were not eligible for early retirement (both after and before its implementation). To do so, I restrict the sample to workers who entered the labor force after 17, and therefore do not qualify for the age of first report criterion of 
eligibility. Once again, the point estimate obtained is very close to the reference one.

Table 4: Effect of extented mandatory retirement: Robustness tests

\begin{tabular}{|c|c|c|c|c|c|c|c|}
\hline & \multicolumn{7}{|c|}{$\mathrm{Y}=$ exit from employment } \\
\hline & $(1)$ & $(2)$ & $(3)$ & $(4)$ & $(5)$ & $(6)$ & $(7)$ \\
\hline & Ref & RT1. & RT2. & RT3. & RT4. & RT5. & RT6. \\
\hline Treatment effect & $\begin{array}{c}0.023^{* *} \\
(0.010)\end{array}$ & $\begin{array}{l}0.018^{*} \\
(0.010)\end{array}$ & $\begin{array}{c}0.030^{* * *} \\
(0.012)\end{array}$ & $\begin{array}{c}0.025^{* *} \\
(0.011)\end{array}$ & $\begin{array}{l}0.021^{*} \\
(0.011)\end{array}$ & & $\begin{array}{c}0.024^{* *} \\
(0.010)\end{array}$ \\
\hline After 2005 & & & & & & $\begin{array}{c}-0.046^{* * *} \\
(0.007)\end{array}$ & \\
\hline After $2005 \times$ pct of treated $(\mathrm{x} 100)$ & & & & & & $\begin{array}{c}0.023^{*} \\
(0.013)\end{array}$ & \\
\hline$R^{2}$ & 0.113 & 0.115 & 0.121 & 0.105 & 0.107 & 0.102 & 0.097 \\
\hline Nb. obs. & 89613 & 89613 & 66631 & 79148 & 74047 & 94045 & 66548 \\
\hline $\mathrm{Nb}$. ind. & 50745 & 50745 & 38510 & 44158 & 41454 & 56673 & 35815 \\
\hline Nb. clusters & 438 & 438 & 376 & 340 & 352 & 556 & 437 \\
\hline Controls & Yes & Yes & Yes & Yes & Yes & Yes & Yes \\
\hline Industry dummies & Yes & Yes & Yes & Yes & Yes & Yes & Yes \\
\hline Year dummies & Yes & Yes & Yes & Yes & Yes & No & Yes \\
\hline
\end{tabular}

${ }^{* * *} p<0.01,{ }^{* *} p<0.05,{ }^{*} p<0.1$

Note: Controls include age dummies, gender dummy, age of entrance in the labor market, and a dummy for being born in France. Standard errors are clustered at the industry level.

SOURCE: Cnav $1 / 20^{\text {th }}$ sample.

READING: The different columns correspond to the six robustness tests implemented (see text for details):

Column (1): Reference (column (3) of Table 3).

Column (2): RT1: Sector of activity x years dummies are added to the main specification.

Column (3): RT2: Only activities with both treated and non-treated workers are kept.

Column (4): RT3: The biggest industry (metal industry) is removed from the sample.

Column (5): RT4: We use another threshold (65\% instead of 50\%) for treatment assignment.

Column (6): RT5: All industry are kept, with an treatment intensity varying according to the proportion of workers with a derogatory agreement in each industry.

Column (7): RT6: Workers potentially impacted by the early retirement reform of 2003 are removed from the sample of estimation.

\subsection{Heterogeneous effects}

In this subsection, the main model is estimated on different sub-populations, not only as additional tests of the robustness of the results, but also, most importantly, as a test for potential heterogeneity in the effect of mandatory retirement. The focus is put on three different types of sub-groups.

Even if we are not able to precisely identify individuals who have reached the full rate with this sample (see section 3 for details and the next section for the focus on the full rate), it is still possible to use the information we have to look for heterogeneous effects. Recall that since the problem is that some periods are not identified in career records (periods worked in other schemes and insurance bonuses for child-bearing), the insurance duration we measure is 
a lower bound. On the other hand, it implies that we are able to identify with certainty some workers who reach the full rate before 65 . Conversely, individuals with very low insurance duration may not be able to reach the full rate before 65 . We then split the sample into the following groups: men (to avoid the children related insurance bonus) who already have the targeted duration when they reach the minimum retirement age $\left(D_{60} \geq D_{F R}\right)$ and those who are much further from $D_{F R}\left(D_{60} \leq D_{F R}-20\right.$ trimesters). Since our treatment (mandatory retirement at full rate before 65) is more likely to hinge on the first group than on the second, the effect is expected to be higher for the former.

We secondly differentiate by earnings, splitting the sample between above and below the median wage at 60 and estimating the model separately for the two populations. The rational is the following. On one hand, the higher the earnings, the stronger is the incentive to keep on working, through both the forgone earnings in case of retirement and the bonus (surcote), which is to some extent proportional to the level of earnings. High earnings is then likely to be positively correlated with a strong willingness to work on the employees' side. On the other hand, firms may want to get rid of high earnings workers in priority, as they put more strain on their wage bill. ${ }^{15}$ The effect of mandatory retirement is then likely to be much stronger for high earnings workers, since they are more willing to work beyond the full rate when they can and firms are more willing to lay them off when possible.

I also differentiate by age group (60 vs. 61-64), without any without preconceived ideas about the potential heterogeneity of the effect within those categories.

Results for those alternative estimations are reported in Table 5. The first column reproduces the third column of Table 3, and the others present results for the estimation of the same model on different sub-samples of the initial sample. Column (2) shows, respectively, the results for male workers with high, middle, and low insurance duration at 60. As expected, the effect of mandatory retirement is mostly driven by individuals with high insurance duration. In column (3), the sample is broken down in two groups of earnings, above and below the median (computed separately in the treated and control groups). Interestingly, it appears that the effect obtained in our main estimation is mostly driven by the upper part of the earnings distribution. The estimated coefficient is almost three times larger for high earnings group compared to low earnings one, and is not significant for the latter. This confirms that mandatory retirement was likely to be particularly used by firms to lay off high earnings workers, who were also those with the strongest incentive to delay retirement.

\footnotetext{
${ }^{15}$ One could think that high earnings workers are also the most productive ones, and therefore firms may want to keep them. But it may not be the case with Lazear-type contracts, in which earnings increases with age without a direct link with productivity (Lazear, 1979).
} 
Table 5: Effect of extented mandatory retirement: heterogeneity

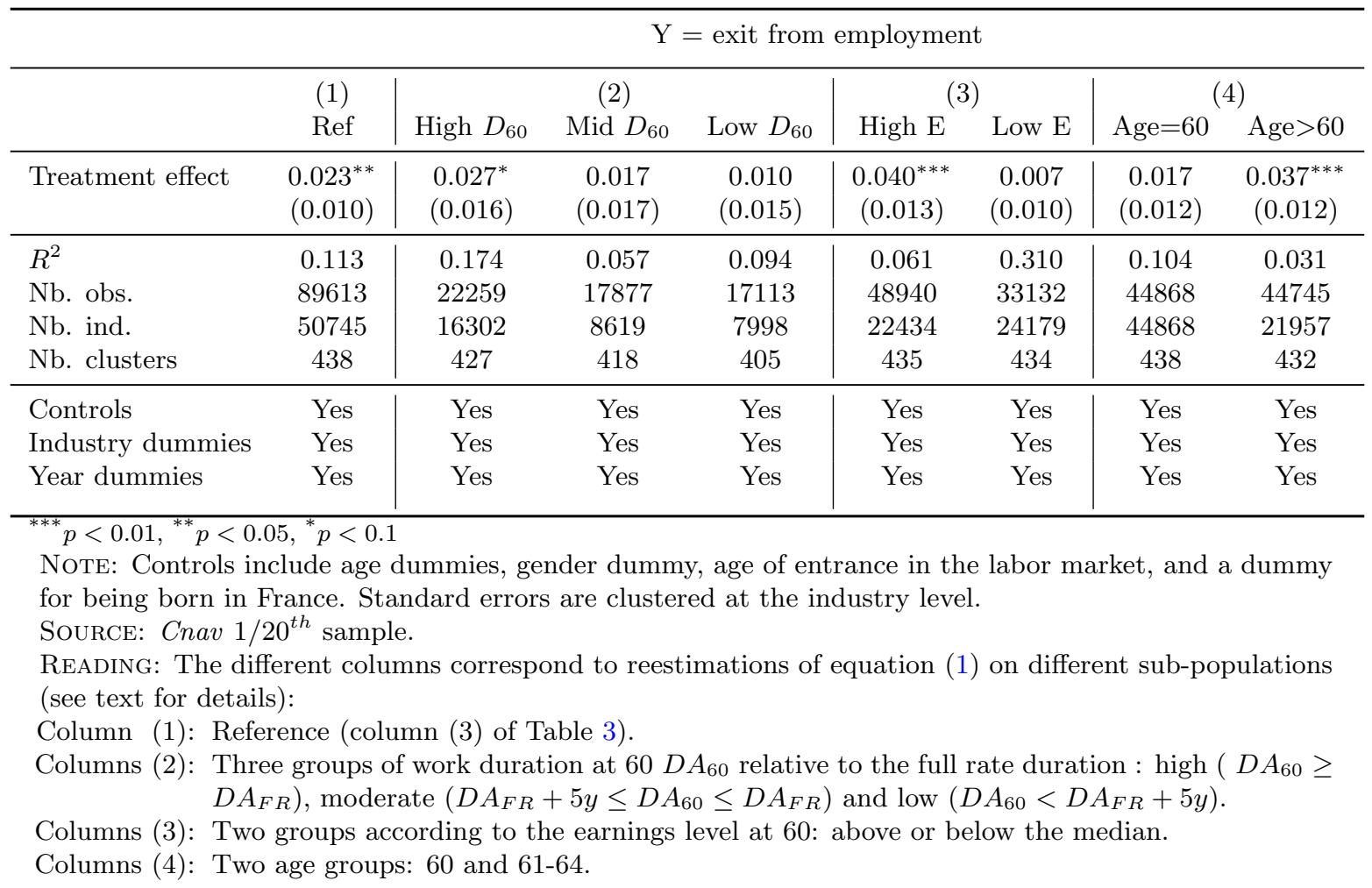

\section{Effect on bunching at full rate}

As it is the case in many other countries (Gruber and Wise, 2004), retirement patterns in France are largely shaped by an important concentration of retirements at key ages of the social security legislation. Figure 5a presents the distribution of claiming age for retirees of our sample who were born before 1948. It exhibits large spikes in retirement distribution in two points: the early retirement age and the normal retirement age (60 and 65, respectively, for those generations). As mentioned in section 2, one important peculiarity of the French system lies in the double condition for a full rate pension: a pensioner gets a full conversion rate of $50 \%$ either by reaching the full rate age of 65 or the full rate work duration, which can be reached at any age from the minimum claiming age. Figure 5b then presents the distribution of the distance to full rate, defined as the minimum number between the distance to the age criteria and to the work duration criteria at claiming age. Almost two-thirds of the sample retires exactly at full rate. It regroups most retirees of the 65 mass, a large part of the 60 one who reach the early retirement age with an important work duration, and some of the retirees in between who reach the full rate between 60 and 65 . This bunching in pension claiming at the full rate has been documented in previous works on French data (for example, Mahieu and Blanchet, 2004), and is likely to have many determinants: financial incentives 
from the pension schedule; credit constraints; norms; and finally mandatory retirement, since full rate eligibility of the worker is a condition for employers to make use of the scheme.

Figure 5: Claiming behavior of generations 1940-1948

(a) Distribution of claiming age

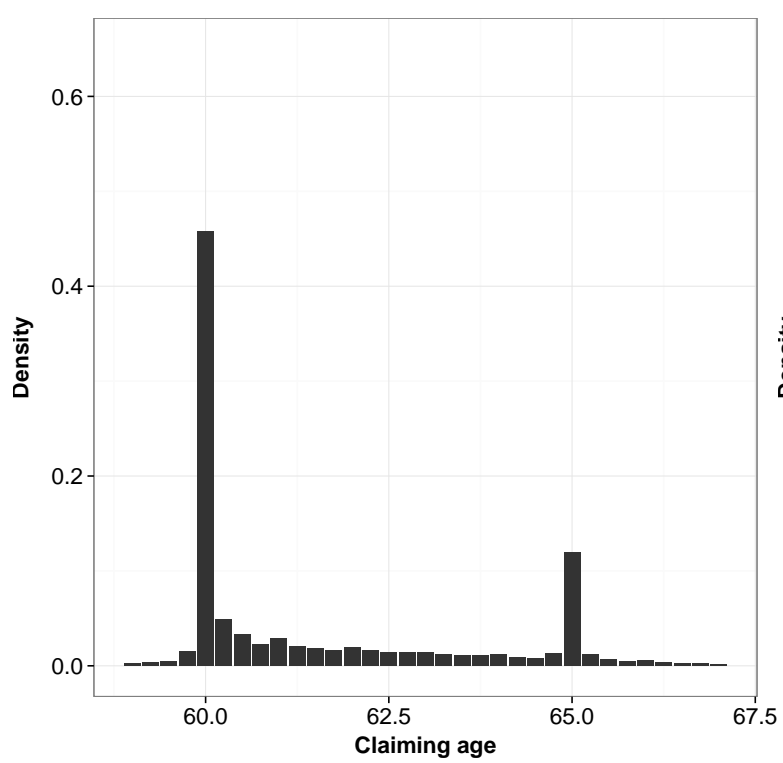

(b) Distribution of distance to full rate

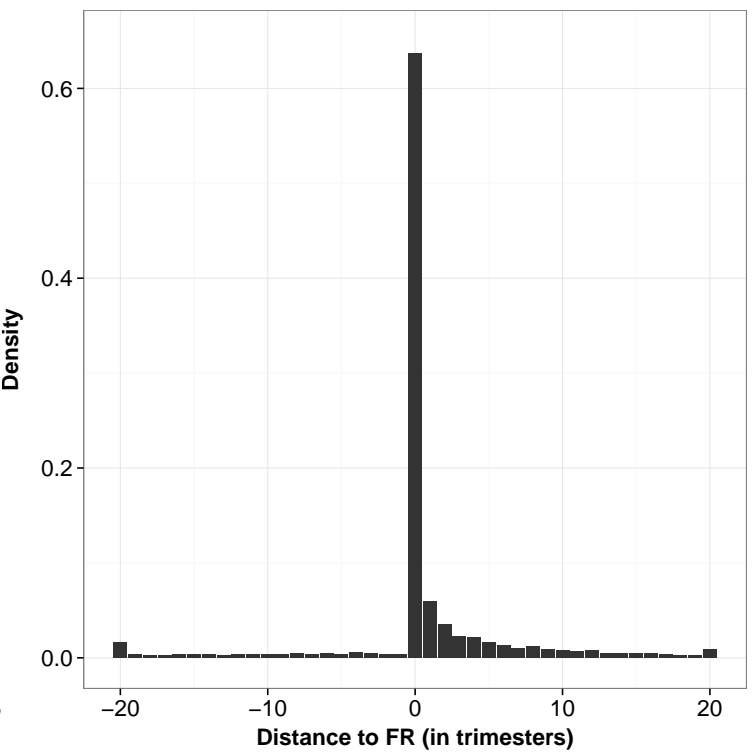

SOURCE: Cnav sample with restrictions described in section 3 and the additional selection of retires of generation 1940-1948.

READING: $17 \%$ of the retirees born in 1940-1948 retired at the normal retirement age of 65 (panel a); $63 \%$ retired at the full rate age (panel b).

In this last part of the paper, we explicitly incorporate eligibility for full rate into the analysis. As explained in section 4, this cannot be done in the main specification, as the full rate variable is reliable only for retirees. On this subpopulation, the model can be enriched with this dimension, as specified in the triple differences specification of equation (2). The objective of this approach is twofold. First, it is an additional test of the robustness of the results, as we verify that the effect we measure in the main specification is driven by individuals eligible for a full rate pension. Second, we can use the point estimates to measure the part of the bunching at full rate that can be attributed to employers' decisions through mandatory retirement.

A first graphical evidence is proposed in Figure 6, reproducing the evolution of job exit rate for the control and treated group, further divided between individuals who are eligible for a full rate pension and individuals who are not. As expected, there seems to be no difference in the evolution of the exit rates for individuals who have not reached their full rate. The pattern observed in Figure 1 seems driven only by the evolution of job exit rate for individuals eligible for a full rate pension. 
Figure 6: Exit rate out of employment by years (between 60 and 64)

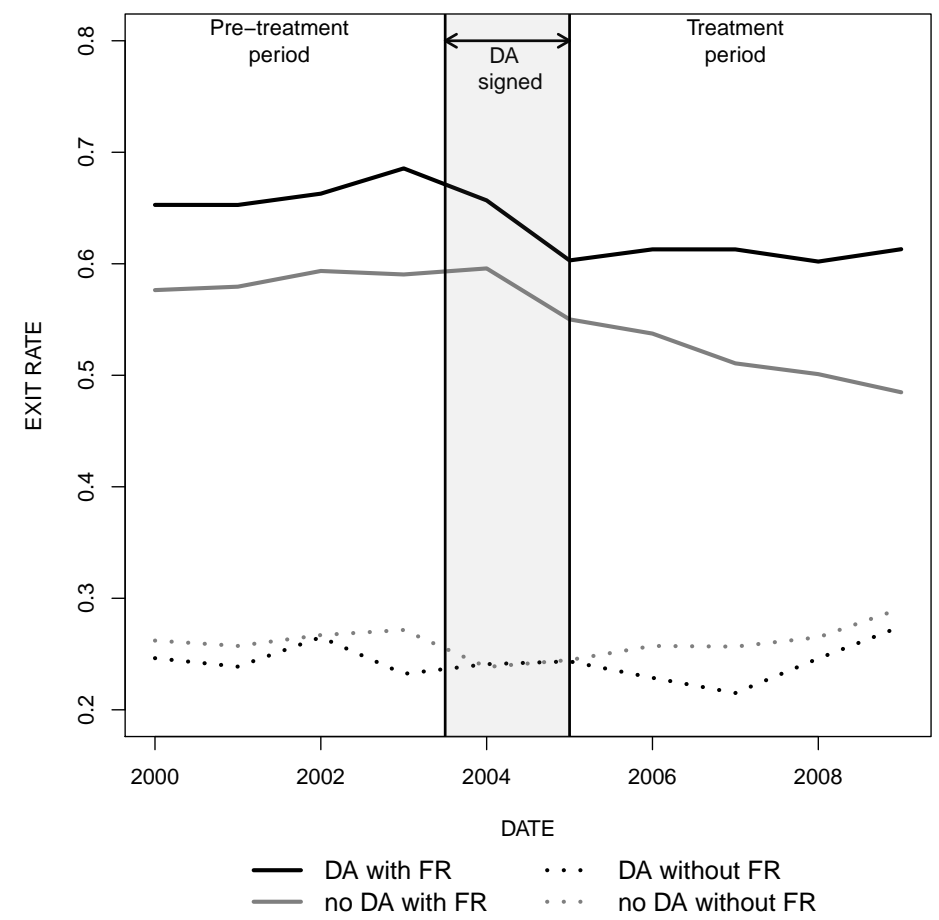

SOURCE: Cnav $1 / 20^{\text {th }}$ sample, retirees only.

READING: See Figure 1. The control and treated group are both split between individuals who are eligible for a full rate pension and individuals who are not.

Table 6 presents the results of the inclusion of the full rate dummies in the main specification. In the first column, the main model of previous subsections is re-estimated on the sub-sample of retirees. The point estimate is a bit smaller than the one found in column (2) of Table 3 but it remains close (2.3pp vs. 2.8pp). In the second column, I replace the interaction with the derogatory agreement by the interaction with the full rate dummy. It first confirms the strong impact of reaching the full rate on exit rate: before 2005, exit rates are estimated to increase by $36 \mathrm{pp}$ when the full rate is reached. The fourth column of Table 6 presents the results of the estimation of equation (2). As expected, there is no detected effect of the derogatory agreements for individuals who have not reached the full rate (After $2005 x$ Full rate coefficient), and the effect of the triple interaction is positive and significant. Results are roughly similar when I use retirement as outcome variables in columns (4) to (6).

Those coefficients can be used to measure the effect of mandatory retirement on bunching at full rate. To do so, I compare the evolution of the effect of the full rate variable for the control and treatment group, before and after the reform. If the impact of the full rate decreases more in the control group, when mandatory retirement is removed, than in the treatment group, this implies that mandatory retirement partly drives bunching at full rate.

Before the reform, the full rate increases by 40pp the probability of exit rates in the treated 
group $\left(\alpha_{3}+\beta_{3}=0.307+0.089=0.40\right)$. In the absence of derogatory agreement, exit rates would have evolved similarly as in the control group, and after 2005 the effect of full rate would have been $0.33\left(0.40+\beta_{2}\right)$ but was instead $0.365(0.33+\delta)$ because of extended mandatory retirement. We then conclude that mandatory retirement explains around $10 \%(3.5 / 36.5)$ of the attraction effect of the full rate. The underlying hypothesis is that, absent the derogatory agreements, job exit at full rate would have evolved similarly in both groups. This seems to be quite a plausible assumption, as previously shown in Figure 6. As underlined before, estimates must be cautiously interpreted since external validity is uncertain: as I estimate the effect of mandatory retirement for industries that signed a derogatory agreement, I only get an upper bound of the effect of mandatory retirement on bunching at full rate for the whole population.

Table 6: Full rate analysis

\begin{tabular}{lcccccc}
\hline & \multicolumn{3}{c}{ Y = job exit } & \multicolumn{3}{c}{ Y = retirement } \\
\hline After 2005 & $-0.036^{* * *}$ & $-0.010^{* *}$ & -0.009 & $-0.021^{* * *}$ & $-0.010^{* *}$ & -0.007 \\
& $(0.008)$ & $(0.005)$ & $(0.007)$ & $(0.007)$ & $(0.004)$ & $(0.006)$ \\
T group & $0.039^{* * *}$ & & -0.005 & 0.009 & & -0.010 \\
& $(0.012)$ & & $(0.013)$ & $(0.011)$ & & $(0.009)$ \\
Full rate & & $0.356^{* * *}$ & $0.307^{* * *}$ & & $0.421^{* * *}$ & $0.396^{* * *}$ \\
& & $(0.013)$ & $(0.016)$ & & $(0.010)$ & $(0.011)$ \\
After 2005 x T group & $0.023^{* *}$ & & -0.002 & $0.018^{*}$ & & -0.005 \\
& $(0.011)$ & & $(0.010)$ & $(0.011)$ & & $(0.009)$ \\
After 2005 x Full rate & & $-0.047^{* * *}$ & $-0.069^{* * *}$ & & $-0.029^{* * *}$ & $-0.049^{* * *}$ \\
& & $(0.010)$ & $(0.012)$ & & $(0.009)$ & $(0.012)$ \\
Full rate x T group & & & $0.089^{* * *}$ & & & $0.045^{* * *}$ \\
& & & $(0.021)$ & & & $(0.017)$ \\
After 2005 x Full rate & & & $0.036^{* *}$ & & & $0.034^{* *}$ \\
x T group & & & $(0.018)$ & & & $0.017)$ \\
\hline$R^{2}$ & 0.112 & 0.184 & 0.190 & 0.145 & 0.260 & 0.261 \\
Nb. obs. & 61730 & 61730 & 61730 & 61730 & 61730 & 61730 \\
Nb. ind. & 36477 & 36477 & 36477 & 36477 & 36477 & 36477 \\
Nb. clusters & 435 & 435 & 435 & 435 & 435 & 435 \\
\hline Controls & Yes & Yes & Yes & Yes & Yes & Yes \\
Year dummies & No & No & No & Yes & Yes & Yes \\
Clusters & Industry & Industry & Industry & Industry & Industry & Industry \\
\hline
\end{tabular}

${ }^{* * *} p<0.01,{ }^{* *} p<0.05,{ }^{*} p<0.1$

Note: Controls include age dummies, gender dummy, age of entrance in the labor market, and a dummy for being born in France, yearly benefits.

Standard errors are clustered at the industry level.

SOURCE: Cnav 1/20 th sample. 


\section{Concluding remarks}

The 2003 reform of the French pension system fostered labor force participation of older workers through both labor demand and labor supply channels: it increased financial incentives to work beyond the full rate age, and forbade mandatory retirement at full rate before 65. Absent the possibility given to firms to keep on the old mandatory retirement scheme through derogatory agreements, it would have been possible to distinguish between the two effects. This paper relies on the industry-level variations induced by the derogatory agreements to isolate the effect of mandatory retirement: employment for the 60-64 age group increased less in firms where mandatory retirement remained possible. Results remain stable through a range of robustness checks. This can be interpreted as first evidence that at least some of the increase in the labor force participation of senior workers observed in France is driven by the demand-side of the labor market.

The overall estimated effect of mandatory retirement is moderate (a $6 \%$ increase in job exit in the presence of mandatory retirement), and admittedly explains only a small part of the fast increase in employment rate of senior workers observed in the last few years. This does not necessarily mean, however, that labor demand is only a minor determinant of labor force participation of older workers, since mandatory retirement is only one part of the story. Firms may influence labor force participation through other channels - hiring or discouragement of older workers, for example - which are not captured in our estimates.

The second main contribution to this paper is to exhibit an original determinant of bunching in retirement patterns at the full rate age. Mandatory retirement is sometimes quoted among the potential drivers of those spikes, but this had never been empirically supported until now. Mandatory retirement is estimated to explain around $10 \%$ of the observed bunching at this point. This demand side dimension of bunching at full rate shall be borne in mind when studying the phenomenon, as neglecting this demand's side dimension could entail an overestimation of the importance of the two main supply-side factors that are commonly put forward, namely financial incentives and norms.

Overall, this paper shows that demand and supply sides of labor force participation go hand in hand and benefit from being studied altogether. Increasing financial incentive to pursuing work can be a relevant tool for raising the employment rate of senior workers, if and only if constraints from the demand side are alleviated at the same time. From a public policy point of view, these results question the strong focus on the supply-side dimension in most reforms aiming at increasing the average retirement age. 


\section{References}

Acemoglu, D., Autor, D. H. \& Lyle, D. (2004), 'Women, war, and wages: The effect of female labor supply on the wage structure at midcentury', Journal of Political Economy $\mathbf{1 1 2}(3), 497-551$.

Adams, S. J. (2004), 'Age discrimination legislation and the employment of older workers', Labour Economics 11(2), 219-241. 00093.

Ashenfelter, O. \& Card, D. (2002), 'Did the Elimination of Mandatory Retirement Affect Faculty Retirement?', American Economic Review 92(4), 957-980.

Autor, D. H. (2003), 'Outsourcing at will: The contribution of unjust dismissal doctrine to the growth of employment outsourcing', Journal of labor economics 21(1), 1-42. 00442.

Behaghel, L. \& Blau, D. M. (2012), 'Framing Social Security Reform: Behavioral Responses to Changes in the Full Retirement Age', American Economic Journal: Economic Policy 4(4), 41-67.

Behaghel, L., Crépon, B. \& Sédillot, B. (2008), 'The perverse effects of partial employment protection reform: The case of french older workers', Journal of Public Economics 92(3), 696-721.

Benallah, S. (2011), 'Comportements de départ en retraite et réforme de 2003. Les effets de la surcote', Economie et statistique 441(1), 79-99.

Bertrand, M., Duflo, E. \& Mullainathan, S. (2004), 'How Much Should We Trust DifferencesIn-Differences Estimates?', The Quarterly Journal of Economics 119(1), 249-275.

Brown, K. M. (2013), 'The link between pensions and retirement timing: Lessons from California teachers', Journal of Public Economics 98, 1-14.

Bur, Y. (2007), Rapport sur le projet de loi de financement de la Sécurité sociale pour 2008, Technical Report number 295, tome I, Assemblée nationale.

Chaslot-Robinet, S. (2008), 'La mise à la retraite d'office', Retraite et société (2), 218-225.

Ciccotelli, M. (2016), 'Le patronat français et la gestion de la main-d?œuvre âgée en france', Retraite et société (1), 65-88.

Coile, C. \& Gruber, J. (2007), 'Future social security entitlements and the retirement decision', The review of Economics and Statistics 89(2), 234-246.

Dorn, D. \& Sousa-Poza, A. (2010), "Voluntary' and 'involuntary' early retirement: an international analysis', Applied Economics 42(4), 427-438. 
Duval, R. (2003), 'The retirement effects of old-age pension and early retirement schemes in OECD countries'.

French, E. (2005), 'The effects of health, wealth, and wages on labour supply and retirement behaviour', The Review of Economic Studies 72(2), 395-427.

Gruber, J. \& Wise, D. (2004), 'Social Security Programs and Retirement around the World: Micro-Estimation', ILR Review 58(2).

Hakola, T. \& Uusitalo, R. (2005), 'Not so voluntary retirement decisions? evidence from a pension reform', Journal of Public Economics 89(11), 2121-2136.

Lazear, E. P. (1979), 'Why is there mandatory retirement?', The Journal of Political Economy pp. 1261-1284. 02232.

Lumsdaine, R. L. \& Mitchell, O. S. (1999), Chapter 49 New developments in the economic analysis of retirement, Vol. 3, Part C, Elsevier, pp. 3261-3307.

Lumsdaine, R. L., Stock, J. H. \& Wise, D. A. (1996), Why Are Retirement Rates So High at Age 65?, Nber chapters, National Bureau of Economic Research, Inc.

Mahieu, R. \& Blanchet, D. (2004), Estimating models of retirement behavior on French data, in 'Social Security Programs and Retirement around the World: Micro-Estimation', University of Chicago Press, pp. 235-284.

Mastrobuoni, G. (2009), 'Labor supply effects of the recent social security benefit cuts: Empirical estimates using cohort discontinuities', Journal of Public Economics 93(11-12), 12241233 .

Neumark, D. (2003), 'Age Discrimination Legislation in the United States', Contemporary Economic Policy 21(3), 297-317.

Neumark, D. \& Stock, W. A. (1999), 'Age Discrimination Laws and Labor Market Efficiency', The Journal of Political Economy 107(5), 1081-1125.

Rust, J. \& Phelan, C. (1997), 'How Social Security and Medicare Affect Retirement Behavior In a World of Incomplete Markets', Econometrica 65(4), 781.

Schirle, T. (2008), 'Why have the labor force participation rates of older men increased since the mid-1990s?', Journal of Labor Economics 26(4), 549-594.

Shannon, M. \& Grierson, D. (2004), 'Mandatory retirement and older worker employment', Canadian Journal of Economics/Revue canadienne d'économique 37(3), 528-551. 


\section{Appendix}

\section{A. Matching methodology for the derogatory agreements}

As explained in subsection 3.2, the extension after 2003 of mandatory retirement before 65 through derogatory agreement, the main treatment variable, is not directly observed and must be matched from external data. In this appendix, we detail the matching method used for our estimation and test the sensitivity of the results to alternative ones.

\section{A.1 Description of the matching methodology}

The goal is to find for each every industry code (code naf) a corresponding collective agreement (CA), using a correspondence table between industry and CA. It gives, for a given year ${ }^{16}$ the percentage of workers attached to the different collective agreements for all existing industry code ${ }^{17}$. As presented at Figure A.1, industry and collective agreements do not exactly match, as the latter is defined according to the type of job; hence, different workers within a same firm can be covered by different collective labor agreements.

Figure A.1: Matching industry and collective agreement

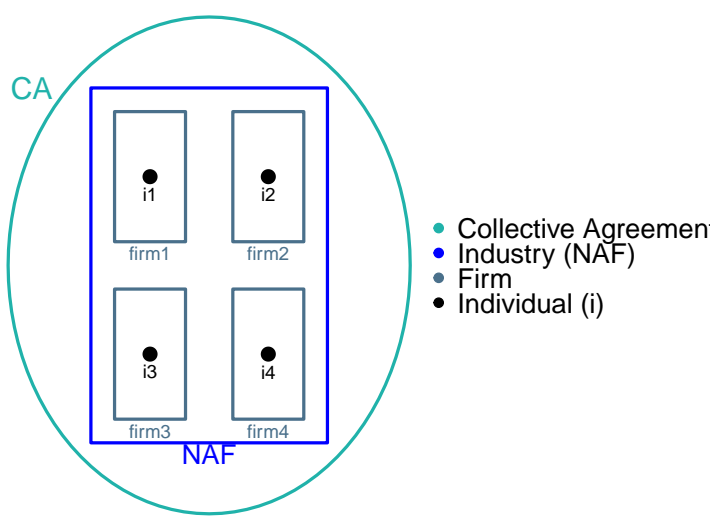

(a) The good case

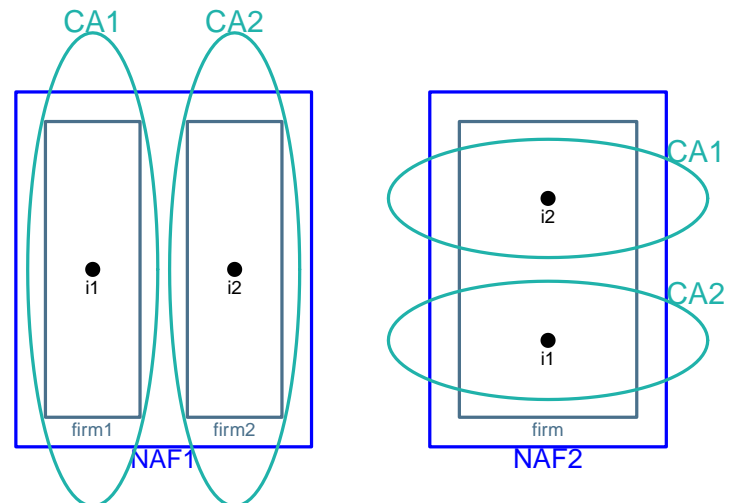

(b) The bad cases

The following matching rule is applied: for each industry we sum the proportion of individuals from each collective labor agreement, and if at least $50 \%$ of its workers are covered by a given collective agreement, we consider that all workers from this industry belongs to the

\footnotetext{
${ }^{16}$ Years 2009 and 2012 are available. Tables are constructed and provided by the French Ministry of Labor (http://travail-emploi.gouv.fr/conventions-collectives, 675/table-de-passage-entre-secteur-d, 14612.html

${ }^{17}$ Information is missing for a non-negligible number of industries (around 20\%). This is the case when an industry is not covered by collective agreement or when it is subject to statistical confidentiality.
} 
latter. Industries for which we do not manage to match a collective agreement are dropped from the estimation sample. The treatment status is inferred from the matched collective labor agreement, and the list of derogatory agreements that have been signed between 2003 and 2006 .

As a result, our main explanatory variable is imprecisely measured: some individuals will be considered as treated at a given date when they are not, and vice versa. The quality of the matching can be assessed using the latest version of the Echantillon inter-régime des retraités ${ }^{18}$ (EIR) that includes direct information on workers' collective agreement from year 2005. We apply our matching methods to the EIR sample, and we can compare the true collective agreement to the imputed one, and then compute to proportion of errors of type I (MR wrongly set to 0) and type II (MR wrongly set to 1). Doing so, we find that we wrongly classify only $10 \%$ of the individuals (see Table A.1) for the baseline sample.

\section{A.2 Alternative matching methods}

In this subsection, alternative matching methodology are implemented. For each one, we provide results on the trade-off between measurement error and selection. We use the EIR dataset to compute the type I (MR wrongly set to 0 ) and type II (MR wrongly set to 1) imputation errors that can be balanced against the implied sample selection. The preferred specification (column 4 of Table 3) is then estimated for each method to assess the sensitivity of our estimation to the imputation process.

\section{A.2.1 Alternative methods tested:}

Two main approaches are considered for constructing the treatment and control groups, using the corresponding table between industries and collective agreements:

M1: For every industry, the CA representing the most workers is attributed as the reference CA, when the CA represents more than $\mathrm{x} \%$ of the industry's workforce. Different values of the threshold $\mathrm{x} \%$ are used: $0 \%$ (the $\mathrm{CA}$ attached is just the maximal pct), $50 \%$, and $75 \%$; respectively, methods M1a, M1b, and M1c). The treatment variable directly stems from that first step: the MR dummy is set to 1 from the date of the derogatory agreement, if one has been signed for the imputed CA.

M2: We sum the percentage of each CA within each industry (with and without derogatory agreement) and we consider as treated the ones for which more than $\mathrm{x} \%$ of the workers belong to a CA with a derogatory agreement. When an industry is treated, we impute as year of implementation of the derogatory agreement the one of the most represented CA. M2a and M2b correspond to the variants with threshold $\mathrm{x}$ equals to 50 and 75 .

\footnotetext{
${ }^{18} \mathrm{~A}$ panel of retirees with administrative career record in most existing pension schemes. See Mahieu and Blanchet (2004) for a detailed presentation of the data.
} 
Two possible designs of the control group are then considered. A first solution is to adopt the same method M1 and M2 for defining the control group. The second one consists in putting every firm that has not been imputed in the treated group as control. This corresponds to M1bis and M2bis models. The method used in the core of the paper is the model M1b: we keep as treated (resp. control) every industry for which at least $50 \%$ of the workforce belong to a CA that signed a DA (resp. that did not sign a DA).

\section{A.2.2 Matching quality}

Table A.1 presents, for each matching method, the proportion of each group (control and treated), and the share of the whole sample it represents. We also compute, on the basis of the observed CA in the EIR dataset, the percentage of misclassification of the treatment variable. There is a trade-off between the sample size and selection on one hand (we want to keep as many workers from the initial sample), and classification errors on the other hand. The lighter the rules to attribute control and treatment status, the bigger the sample and the higher the chance of misclassification. In the "bis" methods, when everything that is not classified as treated is put in the control group, we keep the whole initial sample, but we also make more errors of type I; that is we put a bigger share of treated workers in the control group. When we increase the imputation thresholds (for example, from M1.a to M1.c), we decrease sample size (from $83 \%$ to $34 \%$ of the sample ) but also have more balanced groups in terms of size, and less classification errors. The M1.b method, which is chosen in the core of the paper, keeps a fair share of the initial sample $(42 \%)$ and induces rather small misclassification rates.

Table A.1: Testing alternative imputation methods: matching quality

\begin{tabular}{lc|ccccc|ccccc}
\hline & Ref & M1.a & M1.b & M1.c & M2.a & M2.b & M1bis.a & M1bis.b & M1bis.c & M2bis.a & M2bis.b \\
\hline Number of obs & 223,105 & 185,933 & 93,961 & 75,612 & 110,058 & 96,895 & 223,105 & 223,105 & 223,105 & 223,105 & 223,105 \\
\% initial sample & 1.00 & 0.83 & 0.42 & 0.34 & 0.49 & 0.43 & 1.00 & 1.00 & 1.00 & 1.00 & 1.00 \\
\hline Number of T & 53,454 & 50,045 & 46,381 & 37,574 & 49,231 & 44,206 & 50,045 & 46,381 & 37,574 & 49,231 & 44,206 \\
Share of T & 0.24 & 0.27 & 0.49 & 0.50 & 0.45 & 0.46 & 0.22 & 0.21 & 0.17 & 0.22 & 0.20 \\
Number of NT & 169,651 & 135,888 & 47,580 & 38,038 & 60,827 & 52,689 & 173,060 & 176,724 & 185,531 & 173,874 & 178,899 \\
Share of NT & 0.76 & 0.73 & 0.51 & 0.50 & 0.55 & 0.54 & 0.78 & 0.79 & 0.83 & 0.78 & 0.80 \\
\hline \% wrong match & 0.00 & 0.12 & 0.10 & 0.09 & 0.11 & 0.09 & 0.10 & 0.10 & 0.12 & 0.09 & 0.10 \\
\% good match & 1.00 & 0.88 & 0.90 & 0.91 & 0.89 & 0.91 & 0.90 & 0.90 & 0.88 & 0.91 & 0.90 \\
\% type I error & 0.00 & 0.09 & 0.04 & 0.02 & 0.07 & 0.04 & 0.07 & 0.08 & 0.12 & 0.07 & 0.09 \\
\% type II error & 0.00 & 0.18 & 0.16 & 0.16 & 0.17 & 0.16 & 0.18 & 0.16 & 0.16 & 0.17 & 0.16 \\
\hline
\end{tabular}

Note: $\quad$ T: treated, NT: non treated Type I error: T imputed as NT Type II error: NT imputed as T

\section{A.2.3 Sensitivity of the results to the imputation method:}

In Table A.2, our main specification is estimated with the alternative matching method presented. I only present the main coefficient of interest, the effect of the derogatory agree- 
ment on exit rates. Reassuringly, the estimated effect does not seem to depend too strongly on the imputation method, at least for methods M1 and M2. The effects are, however, smaller and sometimes not significant at the conventional level (though not far from it) for the "bis" models. We interpret this as follows. Applying the same method for selecting the treated and the control group is a way to have more comparable groups, both in terms of size and composition. Presumably, industries for which we are not able to attribute a collective agreement $\mathrm{CA}$ are specific. As mentioned above, the industries we are not able to match with a CA are either those for which information is not available (due to statistical confidentiality) or those for which a majority of workers does not depend on a collective agreement. Applying the same rule for selecting the treated and control groups is then a way to have more comparable groups, with workers of the classic private sector attached to a derogatory agreement. It provides a cleaner identification setting, at the expense of external validity.

Table A.2: Testing alternative imputation methods: estimation sensitivity

\begin{tabular}{lcccccccccc}
\hline & M1.a & M1.b & M1.c & M2.a & M2.b & M1bis.a & M1bis.b & M1bis.c & M2bis.a & M2bis.b \\
\hline Treatment effect & $0.016^{*}$ & $0.022^{* *}$ & $0.024^{* *}$ & $0.017^{* * *}$ & $0.017^{* * *}$ & $0.016^{*}$ & 0.015 & 0.010 & $0.015^{*}$ & 0.014 \\
& $(0.009)$ & $(0.010)$ & $(0.011)$ & $(0.010)$ & $(0.010)$ & $(0.009)$ & $(0.010)$ & $(0.010)$ & $(0.009)$ & $(0.009)$ \\
\hline$R^{2}$ & 0.106 & 0.116 & 0.110 & 0.110 & 0.110 & 0.106 & 0.106 & 0.106 & 0.106 & 0.106 \\
Nb. obs. & 114487 & 88506 & 73246 & 104509 & 92982 & 114487 & 114487 & 114487 & 114487 & 114487 \\
Nb. ind. & 62920 & 49993 & 40901 & 57962 & 51548 & 62920 & 62920 & 62920 & 62920 & 62920 \\
\hline
\end{tabular}




\section{B. List of derogatory agreements}

\begin{tabular}{|c|c|c|c|c|c|}
\hline Count & Industry number & Industry name & Date of signature & Date of implementation & Date of publication the Journal Officiel \\
\hline 1 & 18 & Textile industrie & $04 / 11 / 2003$ & $01 / 01 / 2004$ & $15 / 06 / 2004$ \\
\hline 2 & 43 & Importation exportation commission courtage & $26 / 03 / 2004$ & $01 / 07 / 2004$ & $01 / 01 / 2005$ \\
\hline 3 & 44 & Chimie industrie & $02 / 02 / 2004$ & $01 / 07 / 2004$ & $17 / 06 / 2004$ \\
\hline 4 & 45 & Caoutchouc industrie & $23 / 02 / 2004$ & $01 / 07 / 2004$ & $31 / 07 / 2004$ \\
\hline 5 & 87 & Carrieres materiaux industrie ouvriers & $15 / 11 / 2004$ & $26 / 03 / 2005$ & $24 / 02 / 2005$ \\
\hline 6 & 135 & Carrieres materiaux industrie etam & $15 / 11 / 2004$ & $26 / 03 / 2005$ & $24 / 02 / 2005$ \\
\hline 7 & 211 & Carrieres materiaux industrie cadres & $15 / 11 / 2004$ & $26 / 03 / 2005$ & $24 / 02 / 2005$ \\
\hline 8 & 112 & Laitiere industrie & $15 / 07 / 2005$ & $03 / 09 / 2005$ & 08/03/2006 \\
\hline 9 & 176 & Pharmaceutique industrie & $19 / 01 / 2004$ & $01 / 07 / 2004$ & $17 / 06 / 2004$ \\
\hline 10 & 200 & Exploitations frigorifiques & $10 / 05 / 2004$ & $01 / 07 / 2004$ & $16 / 04 / 2005$ \\
\hline 11 & 275 & Transport aérien personnel au sol & $13 / 04 / 2005$ & $02 / 07 / 2005$ & $25 / 01 / 2006$ \\
\hline 12 & 247 & Habillement industries & $02 / 11 / 2005$ & $07 / 01 / 2006$ & $05 / 04 / 2006$ \\
\hline 13 & 650 & Metallurgie ingenieurs et cadres & $19 / 12 / 2003$ & $01 / 07 / 2004$ & $12 / 05 / 2004$ \\
\hline 14 & 925 & Papiers cartons distribution commerce gros cadres & $20 / 01 / 2005$ & $07 / 05 / 2005$ & $17 / 01 / 2006$ \\
\hline 15 & 802 & Papiers cartons distribution commerce gros oetdam & $20 / 01 / 2005$ & $07 / 05 / 2005$ & $17 / 01 / 2006$ \\
\hline 16 & 716 & Cinema distribution employes et ouvriers & $28 / 04 / 2005$ & $16 / 07 / 2005$ & $08 / 03 / 2006$ \\
\hline 17 & 892 & Cinema distribution cadres et agents de maîtrise & $28 / 04 / 2005$ & $16 / 07 / 2005$ & $08 / 03 / 2006$ \\
\hline 18 & 731 & Quincaillerie commerces cadres & $28 / 06 / 2004$ & $01 / 07 / 2004$ & $28 / 04 / 2005$ \\
\hline 19 & 1383 & Quincaillerie commerces employes & $28 / 06 / 2004$ & $01 / 07 / 2004$ & $28 / 04 / 2005$ \\
\hline 20 & 787 & Experts-comptables et commissaires aux comptes & $12 / 05 / 2004$ & $01 / 07 / 2004$ & $06 / 11 / 2004$ \\
\hline 21 & 1000 & Avocats cabinets personnel salarie & $09 / 07 / 2004$ & $01 / 07 / 2004$ & $31 / 12 / 2004$ \\
\hline 22 & 1043 & Gardiens concierges et employes d'immeubles & $24 / 03 / 2005$ & $18 / 06 / 2005$ & $29 / 10 / 2006$ \\
\hline 23 & 1044 & Horlogerie & $01 / 09 / 2004$ & $21 / 05 / 2005$ & $16 / 04 / 2005$ \\
\hline 24 & 1077 & Produits du sol engrais negoce et industrie & $30 / 03 / 2004$ & $01 / 07 / 2004$ & $28 / 06 / 2005$ \\
\hline 25 & 1090 & Automobile services & $18 / 02 / 2004$ & $01 / 07 / 2004$ & $19 / 08 / 2004$ \\
\hline 26 & 1170 & Tuiles et briques industrie & $20 / 12 / 2004$ & $01 / 07 / 2005$ & $08 / 03 / 2006$ \\
\hline 27 & 1388 & Petrole industrie & $29 / 03 / 2004$ & $01 / 07 / 2004$ & $21 / 07 / 2004$ \\
\hline 28 & 1408 & Combustibles solides liquides gazeux negoce & $07 / 05 / 2004$ & $01 / 07 / 2004$ & $11 / 12 / 2004$ \\
\hline 29 & 1412 & Aeraulique installation entretien reparation & $14 / 06 / 2004$ & $01 / 07 / 2004$ & $26 / 12 / 2004$ \\
\hline 30 & 1483 & Habillement articles textiles commerce de detail & $23 / 11 / 2004$ & $29 / 10 / 2005$ & $06 / 10 / 2005$ \\
\hline 31 & 1486 & Bureaux d'etudes techniques & $11 / 09 / 2003$ & $01 / 07 / 2004$ & $28 / 07 / 2004$ \\
\hline 32 & 1512 & Promotion immobiliere & $20 / 09 / 2004$ & $04 / 06 / 2005$ & $27 / 04 / 2005$ \\
\hline 33 & 1513 & Eaux boissons sans alcool production & $16 / 09 / 2005$ & $10 / 12 / 2005$ & $01 / 01 / 2006$ \\
\hline 34 & 1518 & Animation & $13 / 01 / 2004$ & $01 / 07 / 2004$ & $28 / 07 / 2004$ \\
\hline 35 & 1527 & Immobilier & $25 / 09 / 2005$ & $29 / 04 / 2006$ & $05 / 04 / 2006$ \\
\hline
\end{tabular}




\begin{tabular}{|c|c|c|c|c|c|}
\hline 36 & 1555 & Pharmaceutique produits fabrication commerce & $02 / 05 / 2005$ & $30 / 07 / 2005$ & $05 / 04 / 2006$ \\
\hline 37 & 1586 & Charcutieres industries & $14 / 04 / 2005$ & $27 / 08 / 2005$ & $16 / 03 / 2006$ \\
\hline 38 & 1589 & Mareyeurs-expediteurs & $18 / 03 / 2005$ & $11 / 06 / 2005$ & $10 / 02 / 2006$ \\
\hline 39 & 1621 & Pharmaceutique repartition & $03 / 11 / 2004$ & $27 / 08 / 2005$ & $19 / 07 / 2005$ \\
\hline 40 & 1672 & Assurances societes & $14 / 10 / 2004$ & $13 / 08 / 2005$ & $13 / 08 / 2005$ \\
\hline 41 & 1679 & Assurance inspection societes & $14 / 10 / 2004$ & $13 / 08 / 2005$ & $13 / 08 / 2005$ \\
\hline 42 & 1850 & Avocats salaries & $05 / 11 / 2004$ & $10 / 09 / 2005$ & $26 / 07 / 2005$ \\
\hline 43 & 1942 & Textiles artificiels et synthetiques industries & $19 / 12 / 2003$ & $01 / 07 / 2004$ & $28 / 07 / 2004$ \\
\hline 44 & 1947 & Bois d'oeuvre et produits derives negoce & $02 / 11 / 2005$ & $18 / 02 / 2006$ & $05 / 04 / 2006$ \\
\hline 45 & 2120 & Banques & 29/03/2005 & $21 / 05 / 2005$ & $26 / 07 / 2005$ \\
\hline 46 & 2128 & Mutualites & $29 / 03 / 2005$ & $11 / 06 / 2005$ & $13 / 10 / 2005$ \\
\hline 47 & 2149 & Dechet activites & 09/02/2004 & $01 / 07 / 2004$ & $26 / 11 / 2004$ \\
\hline 48 & 2174 & Navigation interieure marchandises pers sedentaire & $10 / 01 / 2005$ & $19 / 03 / 2005$ & $19 / 10 / 2005$ \\
\hline 49 & 2216 & Commerce detail et gros à predominance alimentaire & 09/06/2004 & $01 / 07 / 2004$ & $25 / 11 / 2004$ \\
\hline 50 & 2264 & Hospitalisation privee & $17 / 03 / 2004$ & $01 / 07 / 2004$ & $02 / 09 / 2005$ \\
\hline 51 & 2272 & Assainissement et maintenance industrielle & $04 / 10 / 2004$ & $01 / 07 / 2005$ & $16 / 04 / 2005$ \\
\hline 52 & 2335 & Assurances agences generales personnel & $28 / 04 / 2004$ & $01 / 07 / 2004$ & $28 / 07 / 2004$ \\
\hline 53 & 2336 & Foyers services jeunes travailleurs organismes & $15 / 09 / 2004$ & $01 / 07 / 2005$ & 08/07/2005 \\
\hline 54 & 2420 & Bâtiment cadres & $01 / 06 / 2004$ & $01 / 07 / 2004$ & $31 / 12 / 2004$ \\
\hline 55 & 2409 & Travaux publics cadres & $01 / 06 / 2004$ & $01 / 07 / 2004$ & $31 / 12 / 2004$ \\
\hline 56 & 2567 & Glaces sorbets crèmes glacées industrie & $13 / 09 / 2004$ & $01 / 07 / 2004$ & $13 / 04 / 2005$ \\
\hline 57 & 2728 & Sucreries, sucreries-distilleries & $14 / 06 / 2005$ & $13 / 08 / 2005$ & $13 / 08 / 2005$ \\
\hline 58 & 1436 & Sucreries, sucreries-distilleries & $14 / 06 / 2005$ & $13 / 08 / 2005$ & $13 / 08 / 2005$ \\
\hline 59 & 3109 & Regroupement industrie alimentaire & $21 / 07 / 2004$ & $01 / 07 / 2004$ & $24 / 04 / 2005$ \\
\hline 60 & 504 & Regroupement industrie alimentaire & $21 / 07 / 2004$ & $01 / 07 / 2004$ & $24 / 04 / 2005$ \\
\hline 61 & 503 & Regroupement industrie alimentaire & $21 / 07 / 2004$ & $01 / 07 / 2004$ & $24 / 04 / 2005$ \\
\hline 62 & 454 & Remontees mecaniques et domaines skiables & $26 / 2005 / 2004$ & $01 / 07 / 2004$ & $12 / 08 / 2005$ \\
\hline 63 & 832 & Ciments industrie fabrication ouvriers & $02 / 04 / 2004$ & $01 / 07 / 2004$ & $28 / 07 / 2004$ \\
\hline 64 & 833 & Ciments industrie fabrication etdam & $02 / 04 / 2004$ & $01 / 07 / 2004$ & $28 / 07 / 2004$ \\
\hline 65 & 493 & Vins, cidres, spiritueux & $10 / 02 / 2005$ & $07 / 05 / 2005$ & $12 / 08 / 2005$ \\
\hline 66 & 2075 & œufs conditionnement transformation & $07 / 04 / 2005$ & $29 / 19 / 2005$ & $05 / 04 / 2006$ \\
\hline 67 & 2410 & Biscotteries chocolateries & $21 / 07 / 2004$ & $01 / 07 / 2004$ & $14 / 02 / 2005$ \\
\hline 68 & 1930 & Meunerie & $27 / 10 / 2004$ & $01 / 07 / 2004$ & $18 / 08 / 2005$ \\
\hline 69 & 2344 & Siderurgie & $18 / 05 / 2004$ & $01 / 07 / 2004$ & $12 / 05 / 2004$ \\
\hline
\end{tabular}

Nоте: This table gathers all the derogatory agreements that were signed between 2003 and 2006, along with the corresponding collective labor agreement for each. 